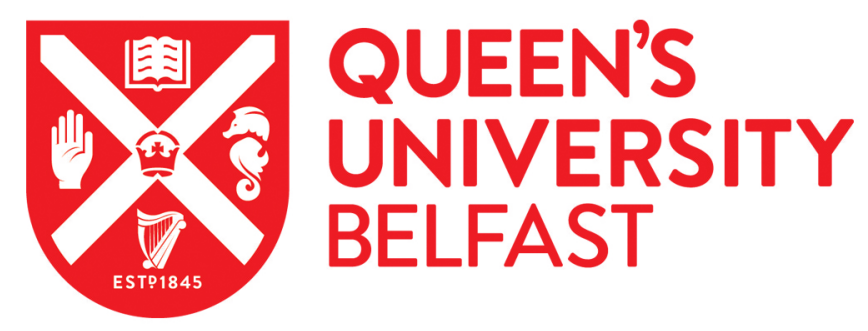

\title{
Remotely Monitored Therapy and Nitric Oxide Suppression Identifies Non-Adherence in Severe Asthma
}

Heaney, L. G., Busby, J., Bradding, P., Chaudhuri, R., Mansur, A. H., Niven, R., Pavord, I. D., Lindsay, J. T., Costello, R. W., \& Medical Research Council UK Refractory Asthma Stratification Programme (RASP-UK) (2019). Remotely Monitored Therapy and Nitric Oxide Suppression Identifies Non-Adherence in Severe Asthma. American Journal of Respiratory and Critical Care Medicine, 199(4), 454-464.

https://doi.org/10.1164/rccm.201806-1182OC

Published in:

American Journal of Respiratory and Critical Care Medicine

\section{Document Version:}

Peer reviewed version

Queen's University Belfast - Research Portal:

Link to publication record in Queen's University Belfast Research Portal

Publisher rights

Copyright $\odot 2018$ by the American Thoracic Society. This work is made available online in accordance with the publisher's policies. Please refer to any applicable terms of use of the publisher.

\section{General rights}

Copyright for the publications made accessible via the Queen's University Belfast Research Portal is retained by the author(s) and / or other copyright owners and it is a condition of accessing these publications that users recognise and abide by the legal requirements associated with these rights.

Take down policy

The Research Portal is Queen's institutional repository that provides access to Queen's research output. Every effort has been made to ensure that content in the Research Portal does not infringe any person's rights, or applicable UK laws. If you discover content in the Research Portal that you believe breaches copyright or violates any law, please contact openaccess@qub.ac.uk. 
Remotely monitored therapy and nitric oxide suppression identifies non-adherence in severe asthma

Liam G Heaney ${ }^{1}$, John Busby ${ }^{1}$, Peter Bradding ${ }^{2}$, Rekha Chaudhuri ${ }^{3}$, Adel H Mansur ${ }^{4}$, Robert Niven $^{5}$, Ian D Pavord ${ }^{6}$, John T Lindsay ${ }^{7}$ and Richard W Costello ${ }^{8}$ on behalf of the Medical Research Council UK Refractory Asthma Stratification Programme (RASP-UK).

${ }^{1}$ Queen's University Belfast, ${ }^{2}$ University of Leicester, ${ }^{3}$ Gartnavel General Hospital and University of Glasgow, ${ }^{4}$ University of Birmingham, ${ }^{5}$ The University of Manchester, ${ }^{6}$ University of Oxford, ${ }^{7}$ Belfast Health and Social Care Trust and ${ }^{8}$ Royal College of Surgeons in Ireland,

Corresponding Author: $\quad$ Professor Liam G Heaney

1.heaney@qub.ac.uk

+44(0)2890976376

Contributions: All authors contributed to study design and set-up, provision of data and review of the manuscript.

Source of support: The service evaluation was embedded in UK Refractory Asthma Stratification Programme with programme support from Aerocrine AB and Vitalograph.

Running title: FeNO suppression to identify adherence in difficult asthma

Descriptor number: 1.11 Clinical Asthma

Research Impact - These data demonstrate that profiling the FeNO and blood eosinophil response 
to inhaled corticosteroids (ICS) in subjects with difficult-to-control severe asthma using remote monitoring technology is useful for clinical phenotyping. It differentiates subjects who will respond well with better adherence to high dose ICS/LABA therapy from those subjects who may require progression to additional treatment. This strategy will be of value in identifying ICS-responsive subjects prior to recruitment to clinical trials investigating interventions which are "add-on" treatments to standard care, and to mechanistic studies investigating "true" inhaled steroid-resistant asthma.

Total word count: 3,427

Online supplement: This article has an online data supplement, which is accessible from this issue's table of content online at www.atsjournals.org

\footnotetext{
At a glance

Scientific Knowledge on the Subject

Non-adherence with inhaled corticosteroids (ICS) in severe asthma is common and consistently associated with poor clinical outcomes. Assessment of adherence to ICS is challenging with physician estimates and patient self-reports overestimating adherence when compared to objective measures. The development and validation of protocol-driven adherence assessments would minimise the risk of committing a patient to long-term biological treatment when their disease is readily controllable with ICS.

\section{What This Study Adds to the Field}

The FeNO suppression test, delivered using remote monitoring technology, is straightforward for both the patient and the clinician, and demonstrates the value of alignment of an ICS responsive biomarker (FeNO) with an inhaler monitoring technology. Profiling the FeNO response to ICS in subjects with difficult-to-control severe asthma is a helpful part of clinical phenotyping, and can identify those who are likely to respond well to high dose ICS/LABA therapy when taken regularly, and those, who despite good adherence with inhaled treatment, are likely to require additional interventions.
} 


\begin{abstract}
Rationale

Poor adherence is common in difficult-to-control asthma. Distinguishing patients with difficult-tocontrol asthma who respond to inhaled corticosteroids (ICS) from refractory asthma is an important clinical challenge.
\end{abstract}

\title{
Objectives
}

Suppression of fractional exhaled nitric oxide (FeNO) with directly observed ICS therapy over 7 days can identify non-adherence to ICS treatment in difficult-to-control asthma. We examined the feasibility and utility of FeNO suppression testing in routine clinical care within UK severe asthma centres using remote monitoring technologies.

\section{Methods}

A web-based interface with integrated remote monitoring technology was developed to deliver FeNO suppression testing. We examined the utility of FeNO suppression testing to demonstrate ICS responsiveness and clinical benefit on electronically-monitored treatment with standard high dose ICS and long-acting $\beta 2$-agonist (LABA) treatment.

\section{Measurements and Main Results}

Clinical response was assessed using the Asthma Control Questionnaire (ACQ-5), spirometry and biomarker measurements (FeNO and peripheral blood eosinophil count). Of 250 subjects, 201 completed the test with 130 positive suppression tests. Compared to a negative suppression test, a positive test identified a FeNO-low population when adherent with ICS/LABA (median 26ppb [IQR 16-36] v 43ppb [IQR 38-73]) with significantly greater $\mathrm{FEV}_{1} \%$ (mean 88.2 $\pm 16.4 v$ 74.1 \pm 20.9 ], $\mathrm{p}<0.01$ ). ACQ-5 improved significantly in both groups (positive test, mean difference $-1.2,95 \%$ CI $-0.9,-1.5$, negative test, mean difference $-0.9,95 \%$ CI $-0.4,-1.3$ ). 


\section{Conclusions}

Remote FeNO suppression testing is an effective means of identifying non-adherence to ICS in subjects with difficult-to-control asthma and the substantial population of subjects who derive important clinical benefits from optimised ICS/LABA treatment.

Total word count of abstract: 250

Indexing terms: asthma, inhaler, monitoring, technology 


\section{Introduction}

Non-adherence with inhaled corticosteroids (ICS) in poorly controlled severe asthma is common and associated with worse clinical outcomes ${ }^{1,2,3}$. Assessment of adherence to inhaled treatments is challenging: physician estimate and patient self-report consistently overestimate adherence when compared to objective measures, and other surrogate measures such as prescription collection records have limitations ${ }^{4,5}$. The advent of novel biologic therapies targeting type- 2 cytokines in severe asthma makes identification of sub-optimal adherence to ICS important so that the issue can be addressed prior to committing a patient to a long-term parenteral therapy. Inhaler monitoring technologies remain the gold standard in clinical trials but clinical services have been slow to embrace these as part of routine care. They are perceived as potentially expensive and cumbersome, and there may be concern from healthcare professionals to challenge non-adherent behaviour or engage subjects to provide long term meaningful change in adherence behaviour.

Suppression of fractional exhaled nitric oxide (FeNO) is an easily measured predictor of ICS response ${ }^{6,7,8}$. Directly observed ICS treatment over seven days in subjects with a high FeNO (FeNO $\geq 45 \mathrm{ppb}$ ) can identify subjects with difficult-to-control severe asthma who are responsive to ICS and non-adherent with their maintenance ICS treatment (FeNO suppression test [FeNOSuppT] - further detail see online supplement $)^{9}$. A value of $\geq 45 \mathrm{ppb}$ was chosen because in subjects with severe asthma, it is associated with frequent exacerbations ${ }^{10}$ and it identifies subjects who respond to treatment with $\mathrm{ICS}^{6,11}$. Thus, in poorly controlled severe asthma and FeNO $\geq 45 \mathrm{ppb}$, the key clinical issue is whether subjects are taking their ICS treatment effectively or whether they need treatment escalation.

The aim of this work was to assess the utility of home-based delivery of the FeNOsuppT using a remote monitoring technology that assess both time of use and inhaler technique thereby enabling "directly observed therapy" to identify subjects who would achieve good asthma control with better 
inhaler technique or adherence to inhaled treatment. Some of the results of this study has been previously reported in the form of an abstract ${ }^{12}$.

\section{Methods}

This was a prospective evaluation of the FeNOsuppT in subjects attending UK severe asthma centres involved in the UK Refractory Asthma Stratification Programme (RASP-UK) ${ }^{13}$ (see online supplement). The Health Research Authority Research UK Ethics Committee and the Research Leads of participating centres approved the study as a clinical service evaluation.

The inhaler monitoring technology used was the INCA ${ }^{\mathrm{TM}}$ device, designed to work with the Diskus $^{\mathrm{TM}}$ inhaler (Figure e1, online supplement) ${ }^{14}$. This acoustic monitoring technology provides a time stamped sound file which can be analysed using an automated validated algorithm providing information on the timing and the technique of inhaler usage (figure e2, online supplement) ${ }^{14}$. FeNO was measured using the Niox VERO ${ }^{\mathrm{TM}}$ and all clinical services were provided with the inhaler monitoring and FeNO technology with appropriate training for clinical staff in its use.

Subjects considered for FeNOsuppT were referrals to a severe asthma clinic with poor asthma control despite prescription of high dose ICS in combination with long-acting $\beta 2$-agonist (ICS/LABA) and an elevated FeNO (defined as FeNO $\geq 45 \mathrm{ppb}$ - high FeNO group). Subjects were asked to measure their FeNO daily and to take high dose ICS for seven days (1000 $\mu$ g fluticasone per day) via the Diskus ${ }^{\mathrm{TM}}$ with an $\mathrm{INCA}^{\mathrm{TM}}$ device, in addition to their usual ICA/LABA. Printed instruction sheets for the inhaler and the Niox VERO were given to each patient.

On return to the clinic, results from both the INCA $^{\mathrm{TM}}$ device and the Niox VERO ${ }^{\mathrm{TM}}$ were uploaded to a server using the Vitalograph IC Data Compression Utility application and analysed using the embedded sound analysis algorithm (Figure e3, online supplement). A FeNOsuppT test was defined 
as previously ${ }^{9}$ but in effect, a $42 \%$ fall in FENO between the Day 0/Day 1 and the Day 4/Day 5 mean values equates to a positive suppression test. If a patient could use the Diskus device efficiently based on the FeNOSuppT monitoring profile, they were offered the opportunity to replace their current ICS/LABA with salmeterol 50 $\mu \mathrm{g} /$ fluticasone $500 \mu \mathrm{g}$ Diskus one inhalation twice per day with an INCA ${ }^{\mathrm{TM}}$ device, and were informed that inhaler use was being monitored for a one month period (Figure e4, online supplement),

After one month of monitoring, the relationship between the FeNOsuppT and biomarker (FeNO and peripheral blood eosinophil count) and clinical outcomes (Asthma Control Questionnaire (ACQ-5) and spirometry) in subjects with good adherence was examined. Good adherence was defined as $\geq 70 \%$ adherence using the INCA ${ }^{\mathrm{TM}}$ device as previously in a clinical trial setting, mean adherence was $73 \%$ using biofeedback and thus likely to be best achievable in a real-world setting ${ }^{14}$.

In parallel, a sub-group of subjects with poor asthma control despite high dose ICS/LABA treatment and $\mathrm{FeNO}<45 \mathrm{ppb}$ at one clinical centre (Belfast) (low FeNO group), were offered INCA $^{\mathrm{TM}}$ monitoring. They were instructed in the use of Accuhaler device, and if they could use it efficiently (based on use of a training device at clinic), they were provided with salmeterol $\left(50 \mu \mathrm{g} /\right.$ fluticasone $500 \mu \mathrm{g}$ Diskus one inhalation twice per day) with an INCA ${ }^{\mathrm{TM}}$ device, to be taken in the morning and in the evening for one month.

\section{Statistical analysis}

Data were anonymised and collected in a systematic manner to allow reporting of the utility of the testing in routine clinical care. Normally distributed variables data were presented using the mean \pm standard deviation. Mean differences were calculated with 95\% confidence intervals, and independent and paired t-tests were used to formally compare between groups. Non-normally distributed variables were presented using the median and the interquartile range. Median 
differences were calculated with bootstrapped $95 \%$ confidence intervals, and the Mann-Whitney U test or Wilcoxon signed-rank test were used to formally compare between groups. Chi-squared tests were used to test for differences across groups for categorical variables. Correlation analyses were conducted using the Spearman's rank test. All statistical analyses were performed using STATA version 14.

\section{Results}

Patient disposition and demographic details for high and low FeNO groups are shown in Figure 1 and Table e1 in the online supplement.

\section{FeNO Suppression test}

Of 250 subjects with $\mathrm{FeNO} \geq 45 \mathrm{ppb}$ who performed a FeNOsuppT, 49 of 250 (20\%) subjects were unable to perform the test - $16(6 \%)$ did not measure their FeNO daily and $33(13 \%)$ had critical inhalation errors or missed multiple doses ( $<70 \%$ of ICS during FeNOSuppT) of the additional inhaler over a single week. This was despite awareness that inhaler usage was being monitored and despite detailed verbal and written instructions, and a proven initial ability to measure their FeNO and use the Diskus efficiently in the clinic.

Of the remaining 201 subjects who successfully performed a FeNOsuppT, 130 (65\%) were positive and 71 had negative tests (35\%) (figure 2, FeNO suppression curves as \% of baseline are shown in figure 5 in the online supplement). Subjects with a positive suppression test had similar levels of FeNO at the start of the test, but were younger $(p<0 \cdot 001)$, more likely to be female $(p=0.007)$, had higher rates of atopic eczema $(\mathrm{p}<0 \cdot 001)$, higher IgE levels $(\mathrm{p}=0.012)$ and were less likely to be on maintenance prednisolone $(\mathrm{p}=0 \cdot 025)($ Table 1$)$. 
There was no difference in baseline FeNO in subjects with a positive suppression test on maintenance prednisolone (median $84 \mathrm{ppb}$, IQR 65, 111) compared to subjects not taking prednisolone (median 92ppb, IQR 63-127) whereas blood eosinophils were significantly lower in subjects on prednisolone (median $0.40 \times 10^{9} / \mathrm{L}$, IQR $0.19,0.61$ versus $0.56 \times 10^{9} / \mathrm{L}$, IQR $0.30-0.84$, $\mathrm{p}<0.01)$. In subjects prescribed maintenance prednisolone, $61(58 \%)$ had a positive suppression test and $45(42 \%)$ had a negative test and there was an identical pattern of FeNO suppression in subjects taking prednisolone compared with subjects not taking prednisolone with no differences in baseline, Day 4 or Day 7 FeNO levels (figure e6 online supplement). This was also was the case in those subjects on maintenance prednisolone with contemporaneous positive prednisolone / cortisol levels on Day 0 (n=59, data not shown).

Blood eosinophil counts (figure 3a and 3b) fell significantly from Day 0 to Day 7 in those subjects who had a positive FeNOsuppT [median difference $=-0.14(95 \% \mathrm{CI}-0.03,-0.23), \mathrm{p}<0.001$ ] but not in subjects with a negative suppression test [median difference $=0.02(95 \% \mathrm{CI}-0.12,0.14)$, $\mathrm{p}=0.684]$. This difference was more apparent for subjects not on maintenance prednisolone; after a positive FeNOsuppT from Day 0 to Day 7 [median difference $=-0.21$ (95\% CI -0.27, -0.11), $\mathrm{p}<0.001$ ] but not in those subjects with a negative suppression test [median difference $=0.06(95 \%$ CI $-0.25,0.45), p=0.842]$ (figure $3 \mathrm{c}$ and $3 \mathrm{~d}$ ). 
Figure 1. Flow diagram showing the disposition of subjects assessed by severe asthma services with difficult-to-control asthma $(n=290)$. Subjects with $\mathrm{FeNO} \geq 45 \mathrm{ppb}$ (multicentre high FeNO group, $n=250$ ) had FeNO suppression testing and if they liked the Diskus and could use the device proficiently proceeded to one month monitored treatment with high dose ICS/LABA (salmeterol $50 \mu \mathrm{g} /$ fluticasone $500 \mu \mathrm{g}$ Diskus one inhalation twice per day). Subjects with FeNO<45ppb (single centre low FeNO group, $n=40$ ) had identical one month monitored treatment.

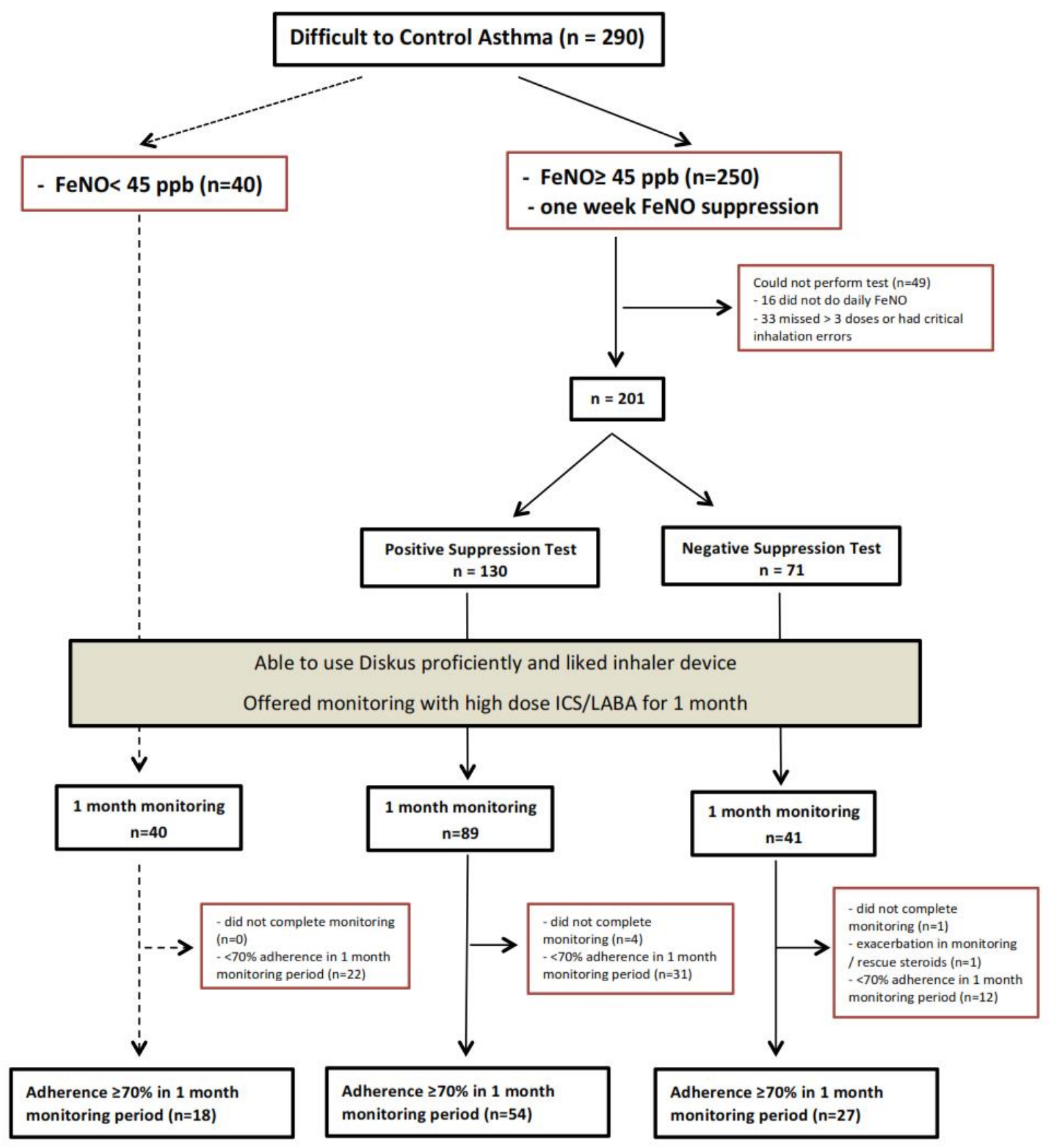


Table 1. Baseline patient characteristics of the 201 subjects with FeNO $\geq 45 p p b$ who successfully performed a FeNO suppression test. Data are shown as median (IQR), mean (SD) or $\mathrm{n}(\%)$ as appropriate.

\begin{tabular}{|c|c|c|c|}
\hline & $\begin{array}{l}\text { Positive FeNO } \\
\text { suppression test } \\
(n=130)\end{array}$ & $\begin{array}{l}\text { Negative FeNO } \\
\text { suppression test } \\
(n=71)\end{array}$ & $P$ value \\
\hline Female, n (\%) & $86(66.2 \%)$ & $33(46.5 \%)$ & 0.007 \\
\hline Age, (years) & $38.8(15.4)$ & $49.8(13.8)$ & $<0.001$ \\
\hline Smoking, n (\%) & & & 0.539 \\
\hline Never smoked & 100 (76.9\%) & 54 (76.1\%) & \\
\hline Ex-smoker & $26(20.0 \%)$ & $16(22.5 \%)$ & \\
\hline Current smoker & $2(1.5 \%)$ & $0(0.0 \%)$ & \\
\hline \multicolumn{4}{|l|}{ Data not available $(n=3)$} \\
\hline Atopic, $\mathbf{n}(\%)^{\text {a }}$ & $84(64.6 \%)$ & $39(54.9 \%)$ & 0.102 \\
\hline \multicolumn{4}{|l|}{ Data not available $(n=4)$} \\
\hline ACQ-5 & $3.0(1.4)$ & $2.5(1.4)$ & 0.028 \\
\hline FeNO (ppb) & $85(64,125)$ & $78(57,118)$ & 0.251 \\
\hline Eosinophils ( cellsx109/L) & $0.50(0.22,0.79)$ & $0.39(0.25,0.65)$ & 0.428 \\
\hline Inhaled steroid (BDP equivalent $\mu \mathrm{g})^{\mathrm{b}}$ & $1727(757)$ & $1670(643)$ & 0.598 \\
\hline On maintenance prednisolone, $\mathrm{n}(\%)$ & $61(46.9 \%)$ & 45 (63.4\%) & 0.025 \\
\hline Prednisolone dose $(\mathrm{mg})$ & $12.7(7.9)$ & $10.5(6.3)$ & 0.137 \\
\hline Hospital admission past 12 months, $n(\%)$ & & & 0.227 \\
\hline 0 & 80 (61.5\%) & $51(71.8 \%)$ & \\
\hline 1 & $19(14.6 \%)$ & $13(18.3 \%)$ & \\
\hline 2 & $10(7.7 \%)$ & $3(4.2 \%)$ & \\
\hline $3+$ & $17(13.1 \%)$ & $4(5.6 \%)$ & \\
\hline \multicolumn{4}{|l|}{ Data not available $(n=4)$} \\
\hline $\begin{array}{l}\text { Unscheduled attendance with asthma (GP or } \\
\text { ER) past } 12 \text { months }\end{array}$ & $2(0,6)$ & $3(1,5)$ & 0.791 \\
\hline $\begin{array}{l}\text { Ever admitted to an Intensive Care Unit, } n(\%) \\
\text { Data not available }(n=4)\end{array}$ & $14(10.8 \%)$ & $12(16.9 \%)$ & 0.249 \\
\hline $\begin{array}{l}\text { Ever invasive ventilation, } \mathbf{n}(\%) \\
\text { Data not available }(n=14)\end{array}$ & $8(6.2 \%)$ & $6(8.5 \%)$ & 0.600 \\
\hline $\begin{array}{l}\text { Eczema, } \mathbf{n}(\%) \\
\quad \text { Data not available }(n=13)\end{array}$ & $31(23.8 \%)$ & $4(5.6 \%)$ & $<0.001$ \\
\hline $\begin{array}{l}\text { Nasal polyps, } \mathbf{n}(\%) \\
\quad \text { Data not available }(n=16)\end{array}$ & $30(23.1 \%)$ & $24(33.8 \%)$ & 0.197 \\
\hline $\mathrm{FEV}_{1}(\%)$ & $75.5(19.7)$ & $68.6(19.0)$ & 0.020 \\
\hline FVC (\%) & $90.9(17.0)$ & $86.5(21.0)$ & 0.118 \\
\hline FEV $_{1} /$ FVC (\%) & $69.2(12.3)$ & $64.6(11.6)$ & 0.013 \\
\hline $\operatorname{lgE}(\mathbf{k U} / \mathrm{L})$ & $282(93,754)$ & $147(72,285)$ & 0.012 \\
\hline
\end{tabular}

$a=$ atopy defined with immunology test; skin prick or RAST positive to inhaled perennial allergen (cat, dog, house dust mite, mixed grasses) $b=$ baseline dose of inhaled steroid as prescribed are equivalent dose of beclomethasone dipropionate (BDP) 
Figure 2. FeNO suppression curves (shown as median values, IQR) for subjects with initial $\mathrm{FeNO} \geq 45 \mathrm{ppb}$ and a positive suppression test (figure $2 \mathrm{a}, \mathrm{n}=130$ ) and a negative suppression test (figure 2b, n=71). Insert figures are median FeNO (IQR) for Day 0, 4 and 7.

\section{Figure 2a}

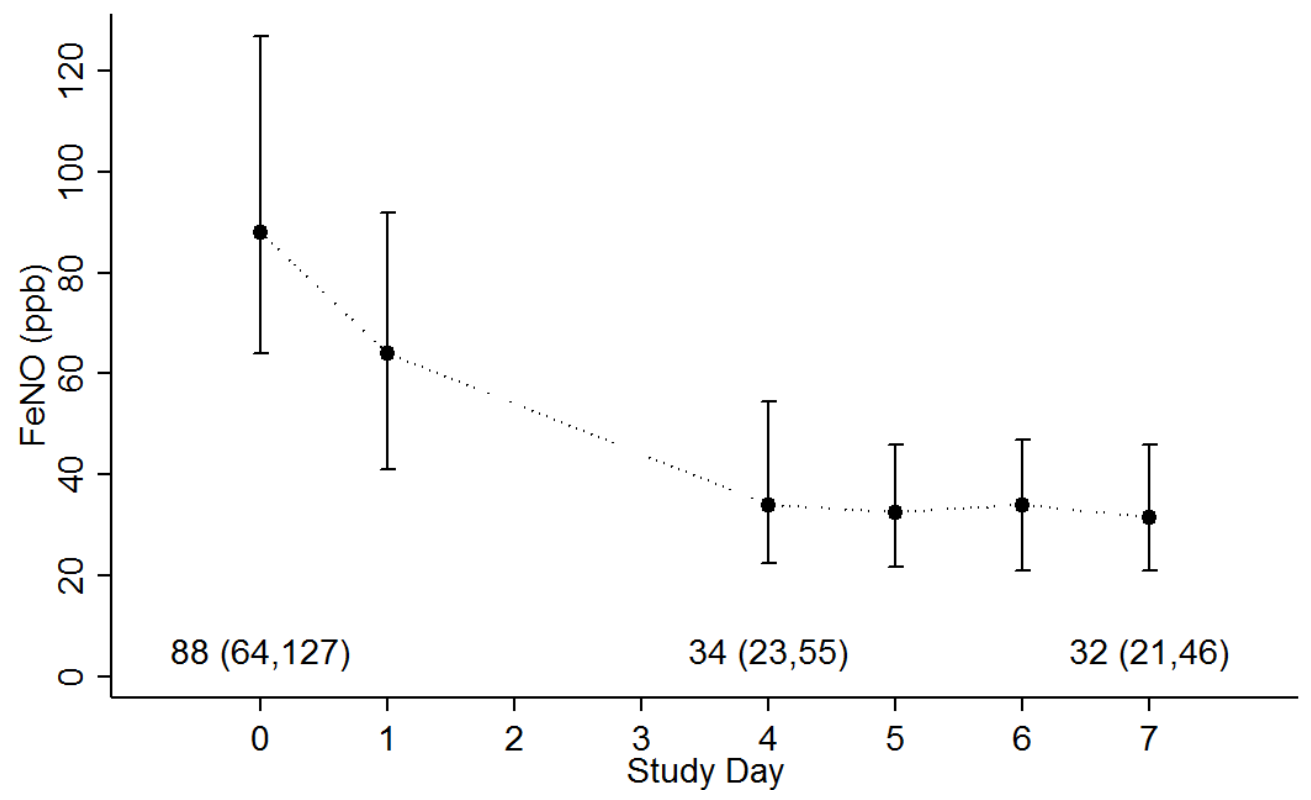

\section{Figure 2b}

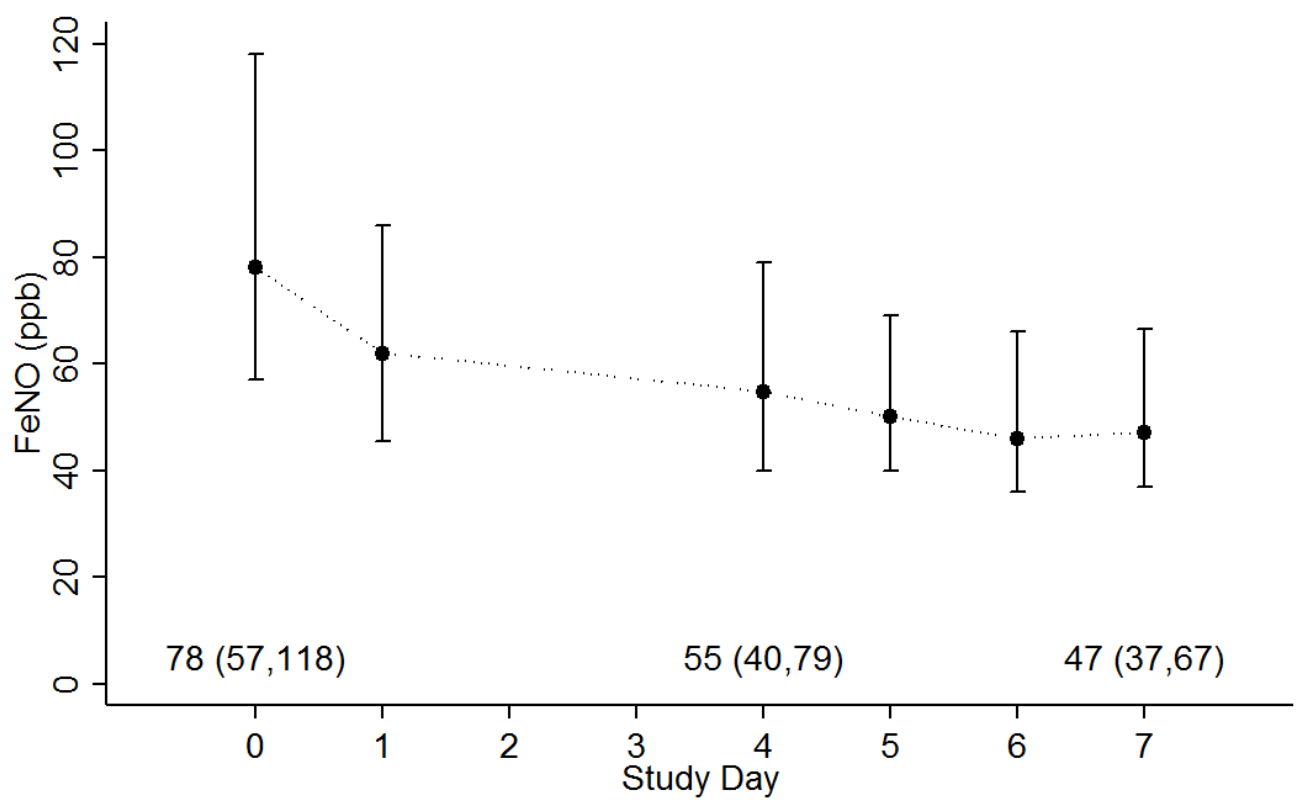


Table 2. Baseline patient characteristics of the subjects who proceeded to 1 month monitoring with high dose ICS/LABA (salmeterol 50 $\mu$ g/fluticasone $500 \mu \mathrm{g}$ Diskus one inhalation twice per day) - FeNO $\geq 45 \mathrm{ppb}$ and positive suppression test, $\mathrm{n}=89$ ), FeNO $\geq 45 \mathrm{ppb}$ and negative suppression test, $\mathrm{n}=41$ and FeNO<45ppb (single centre low FeNO group, $\mathrm{n}=40$ ) had identical one month monitored treatment. Data are shown as median (IQR), mean (SD) or $\mathrm{n}(\%)$ as appropriate.

\begin{tabular}{|c|c|c|c|c|c|}
\hline & \multirow[b]{2}{*}{$\begin{array}{l}\text { FeNO Low } \\
(n=40)\end{array}$} & \multicolumn{2}{|c|}{ FeNO High } & \multirow[b]{2}{*}{$\begin{array}{l}\text { FeNO Low versus } \\
\text { Positive Suppression }\end{array}$} & \multirow[b]{2}{*}{$\begin{array}{l}\text { FeNO Low versus } \\
\text { Negative Suppression }\end{array}$} \\
\hline & & $\begin{array}{c}\text { Positive FeNO } \\
\text { suppression test }(n=89)\end{array}$ & $\begin{array}{c}\text { Negative FeNO } \\
\text { suppression test }(n=41)\end{array}$ & & \\
\hline Female, n (\%) & $30(75.0 \%)$ & $58(65.2 \%)$ & $18(43.9 \%)$ & 0.267 & 0.004 \\
\hline Age (years) & $46.5(12.6)$ & $39.1(15.3)$ & $47.4(15.1)$ & 0.009 & 0.769 \\
\hline Smoking; n (\%) & & & & 0.313 & 0.403 \\
\hline Never smoked & $26(65.0 \%)$ & $69(77.5 \%)$ & $31(75.6 \%)$ & & \\
\hline Ex-smoker & $13(32.5 \%)$ & $18(20.2 \%)$ & $10(24.4 \%)$ & & \\
\hline Current smoker & $1(2.5 \%)$ & $2(2.2 \%)$ & $0(0.0 \%)$ & & \\
\hline Atopic, n (\%) & $20(50.0 \%)$ & $59(66.3 \%)$ & $22(53.7 \%)$ & 0.066 & 0.742 \\
\hline ACQ-5 & $2.6(1.4)$ & $2.8(1.4)$ & $2.7(1.4)$ & 0.306 & 0.699 \\
\hline FeNO (ppb) & $28(14,36)$ & $85(65,122)$ & $83(59,114)$ & $<0.001$ & $<0.001$ \\
\hline Blood eosinophils (x109/L) & $0.24(0.10,0.50)$ & $0.44(0.21,0.80)$ & $0.36(0.22,0.64)$ & 0.005 & 0.146 \\
\hline Inhaled steroid (BDP equivalent $\mu \mathrm{g})^{b}$ & $1642(400)$ & $1659(662)$ & $1732(748)$ & 0.883 & 0.514 \\
\hline On maintenance prednisolone, $n$ (\%) & $23(57.5 \%)$ & $41(46.1 \%)$ & $22(53.7 \%)$ & 0.230 & 0.728 \\
\hline Prednisolone dose $(\mathrm{mg})$ & $10.6(5.5)$ & $11.6(6.2)$ & $11.2(7.8)$ & 0.513 & 0.750 \\
\hline \multicolumn{6}{|l|}{ Hospital admission past 12 months, $n$} \\
\hline (\%) & & & & 0.076 & 0.743 \\
\hline 0 & $25(62.5 \%)$ & $59(66.3 \%)$ & $30(73.2 \%)$ & & \\
\hline 1 & $12(30.0 \%)$ & $12(13.5 \%)$ & $8(19.5 \%)$ & & \\
\hline 2 & $1(2.5 \%)$ & $7(7.9 \%)$ & $1(2.4 \%)$ & & \\
\hline $3+$ & $2(5.0 \%)$ & $11(12.4 \%)$ & $2(4.9 \%)$ & & \\
\hline \multicolumn{6}{|l|}{ Unscheduled attendance with asthma } \\
\hline (GP or ER) past 12 months & $4(2,10)$ & $2(0,7)$ & $4(1,6)$ & 0.074 & 0.230 \\
\hline Ever admitted to an Intensive Care & & & & & \\
\hline Unit; n (\%) & $3(7.5 \%)$ & $9(10.1 \%)$ & $4(9.8 \%)$ & 0.637 & 0.718 \\
\hline Ever invasive ventilation, $\mathrm{n}(\%)$ & $2(5.0 \%)$ & $6(6.7 \%)$ & $1(2.4 \%)$ & 0.650 & 0.556 \\
\hline Data not available $(n=6)$ & $0(0.0 \%)$ & $5(5.6 \%)$ & $1(2.4 \%)$ & & \\
\hline Eczema; n (\%) & $6(15.0 \%)$ & $23(25.8 \%)$ & $3(7.3 \%)$ & 0.136 & 0.271 \\
\hline \multirow{3}{*}{$\begin{array}{l}\text { Data not avallable }(n=4) \\
\text { Nasal polyps; } \boldsymbol{n}(\%)\end{array}$} & & & & & \\
\hline & $12(30.0 \%)$ & $19(21.3 \%)$ & $14(34.1 \%)$ & 0.416 & 0.689 \\
\hline & & 11 & & & \\
\hline
\end{tabular}


Data not available $(n=7)$

\begin{tabular}{lccrr} 
FEV (\%) & $75.6(19.9)$ & $79.2(18.5)$ & $68.9(17.6)$ & 0.341 \\
FVC (\%) & $90.0(18.1)$ & $93.9(16.3)$ & $83.5(21.1)$ & 0.126 \\
FEV 1 /FVC (\%) & $67.3(11.6)$ & $69.7(10.5)$ & $66.7(11.0)$ & 0.155 \\
IgE (kU/L) & $108(48,303)$ & $332(99,750)$ & $194(93,381)$ & 0.268 \\
\hline
\end{tabular}

$a=$ atopy defined with immunology test; skin prick or RAST positive to inhaled perennial allergen (cat, dog, house dust mite, mixed grasses) $b=$ baseline dose of inhaled steroid as prescribed are equivalent dose of beclomethasone dipropionate (BDP) 
Figure 3. Blood eosinophils on Day 0 and Day 7 of the FeNO Suppression test in subjects with positive (figure $3 \mathrm{a}, \mathrm{n}=83$ ) and negative (figure $3 \mathrm{~b}, \mathrm{n}=37$ ) suppression tests and in subjects not on maintenance prednisolone with positive (figure $3 \mathrm{c}, \mathrm{n}=49$ ) and negative suppression tests (figure $3 \mathrm{~d}$, $\mathrm{n}=15$ ). Data is shown as median (IQR).

Figure 3a

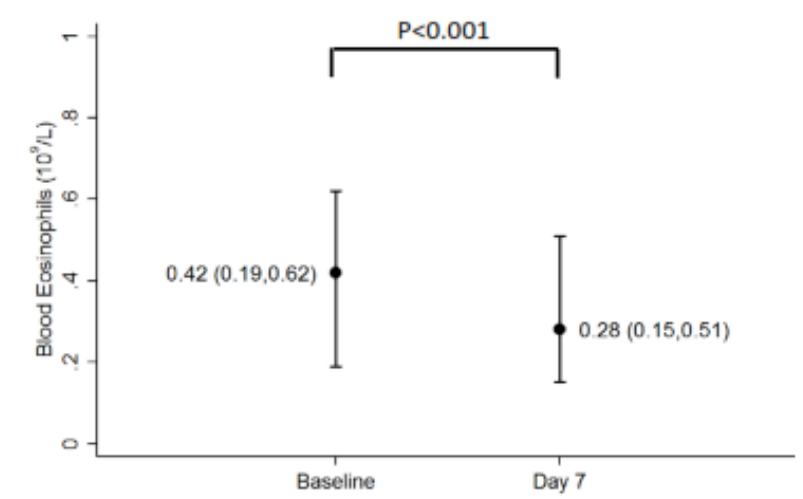

Figure 3c

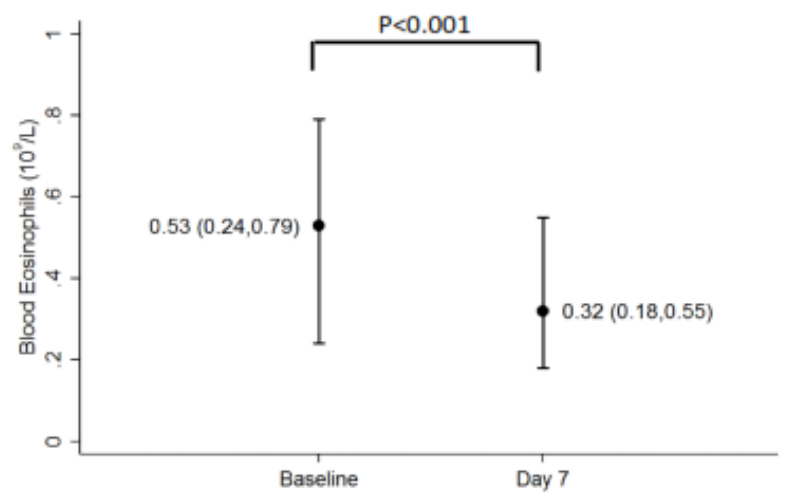

Figure 3b

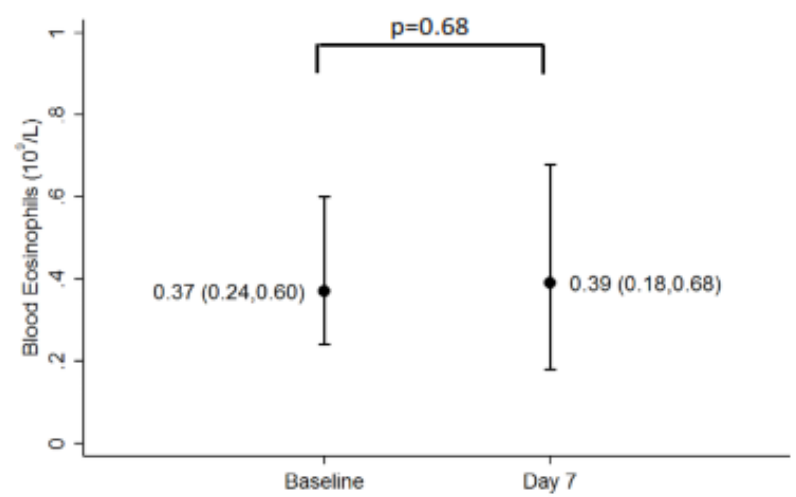

Figure 3d

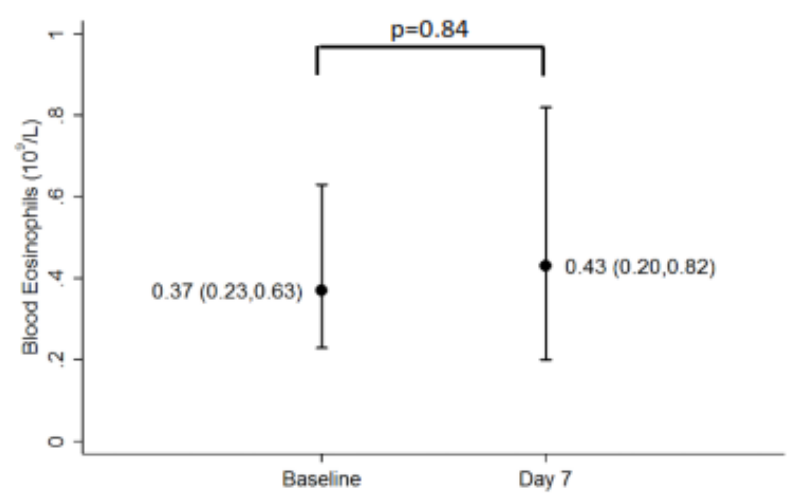

\section{Post one month monitoring after FeNO suppression test}

Of the subjects who successfully performed suppression testing, 130 subjects agreed to proceed to further monitoring for one month to assist with use of their inhaled treatment $89(68 \%)$ with a positive test and $41(58 \%)$ with a negative test (table 2). All of these subjects could use the Diskus device proficiently based on monitoring during the suppression test. Of these, 1 patient with a negative suppression test required a rescue course of steroids during the monitoring month and 5 subjects did not complete monitoring. After performing 1 month monitoring, 54 of 85 subjects (64\%) with a positive suppression test and 27 of 39 subjects (69\%) with a negative suppression test had $\geq 70 \%$ adherence with salmeterol $50 \mu \mathrm{g} /$ fluticasone $500 \mu \mathrm{g}$ Diskus (mean adherence $81 \pm 12 \%$ 
positive test versus $84 \pm 9 \%$ negative test). For subjects who failed to achieve $\geq 70 \%$ adherence during the 1 month monitoring period, both critical inhaler technique error and missed doses were common problems with mean adherence $45 \pm 18 \%$.

There was a strong relationship between FeNO at Day 7 of the FeNOsuppT and FeNO level after one month monitored treatment with good adherence which was also the case for subjects on maintenance prednisolone (figure 4). There was also a significant reduction in blood eosinophil counts in subjects with a positive suppression test and monitored good adherence over one month who were not taking prednisolone (median difference -0.25 (95\% CI $-0.37,-0.03, \mathrm{p}<0.001)$, figure 5c), which was not seen in those with a negative suppression test (median difference 0.11 (95\% CI $0.13,0.19, \mathrm{p}=0.88)$, figure $5 \mathrm{~d})$. A similar trend was observed when subjects on prednisolone were included (median difference -0.06 (95\% CI -0.17, 0.02, p=0.054, figure 5a) however this just failed to reach statistical significance because as discussed above subjects on prednisolone had lower baseline blood eosinophil counts (figure 5); again, there was no difference in subjects with a negative suppression test (median difference $-0.03 .95 \% \mathrm{CI}-0.13,0.08, \mathrm{p}=0.71$, figure $5 \mathrm{~b}$ ). The correlation between the day-7 biomarkers after FeNOSuppT and post one month monitoring values is shown in Figure $6(\mathrm{FeNO}, \mathrm{r}=0.69 ; \mathrm{p}<0 \cdot 001$, blood eosinophils $r=0.60 ; \mathrm{p}<0 \cdot 001)$ with post one month monitoring FeNO generally lower than day-7 FeNO value.

\section{Predictive value of FeNO Suppression test}

We also examined the predictive value of a positive 7-day suppression test for FeNO level in subjects with good adherence after one month monitoring, using Receiver Operating Characteristic (ROC) analysis (Figure e7, online supplement). The area under the curve was 0.81 (95\% CI, 0.720.91) and the optimal cut-point for specificity and sensitivity was FeNO 35ppb (in severe asthma, FeNO $<35 \mathrm{ppb}$ has been shown to be associated with significantly less airway reactivity, airflow limitation and hyperinflation and significantly reduced emergency room and intensive care unit 
admissions ${ }^{15}$ ). The sensitivity of a positive FeNOsuppT for post monitoring FeNO $\leq 35 \mathrm{ppb}$ when adherent with treatment was 89\% (95\% CI, 76-96\%) and specificity 61\% (95\% CI, 44-77\%). In terms of predictive value, 40 of 54 positive tests had a post one month monitoring FeNO $\leq 35 \mathrm{ppb}$ and 22 of 27 negative tests had a FeNO>35ppb giving a positive predictive value for a FeNO $\leq 35 \mathrm{ppb}$ of $74 \%$ [95\% CI, 65-81\%] and a negative predictive value of $82 \%$ [95\% CI, 65$91 \%$ ]. For the 14 of 54 subjects with FeNO>35ppb after 1 month monitoring, there was still significant suppression (baseline FeNO 97ppb [IQR, 81 - 190], Day 740 ppb [IQR, 32 - 69], Day 30 57ppb [IQR $41-68], \mathrm{p}<0.001)$.

\section{FeNO low group}

In the low FeNO group ( $<45 \mathrm{ppb})$, who proceeded to monitoring for one month $(\mathrm{n}=40$, Table 2$)$, again, despite being able to use the Diskus efficiently based on the initial dose taken in clinic and being informed and aware that they were being monitored, only 18 of 40 subjects (45\%) achieved adherence $\geq 70 \%$ over the one month monitoring period (mean adherence $82 \pm 8 \%$ ). For FeNO low subjects who failed to achieve $\geq 70 \%$ adherence during the 1 month monitoring period, both critical inhaler technique error and missed doses were again common with mean adherence $35 \pm 21 \%$. For those subjects who were adherent over the 1 month period $(n=18)$, there was a small change in FeNO (baseline median FeNO 32ppb, IQR 21, 41, post monitoring median FeNO 22.5ppb, IQR 16, 35, $\mathrm{p}=0.045$ ). There was no significant difference in blood eosinophil count (baseline median 0.26, IQR $0.17-0.52$ versus post month median 0.27 , IQR $0.10,0.48, \mathrm{p}=0.776$ ) irrespective of being prescribed maintenance prednisolone. 
Figure 4. Relationship between FeNO after 7-day suppression testing and FeNO after one month monitoring for subjects with good adherence (a) positive suppression test $(n=54)$ and (b) negative suppression test $(\mathrm{n}=27)$. The same pattern was seen in subjects on prednisolone with good adherence (c) positive suppression test $(n=28)$ and $(d)$ negative suppression test $(n=15)$. Insert figures are median FeNO (IQR).

Figure 4a

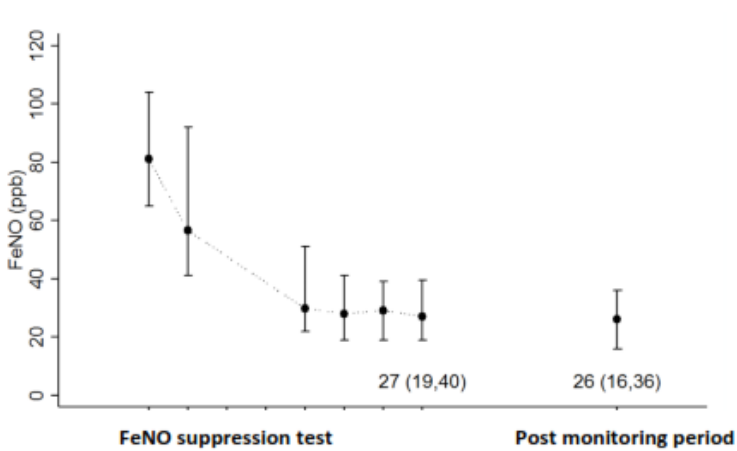

Figure 4b

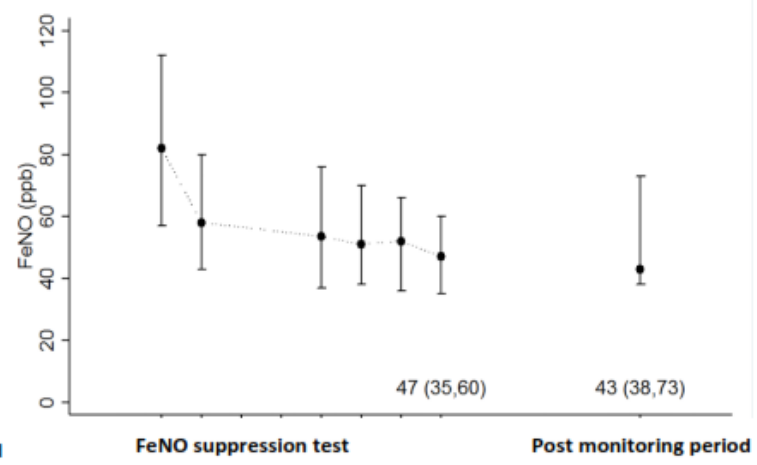

Figure 4c

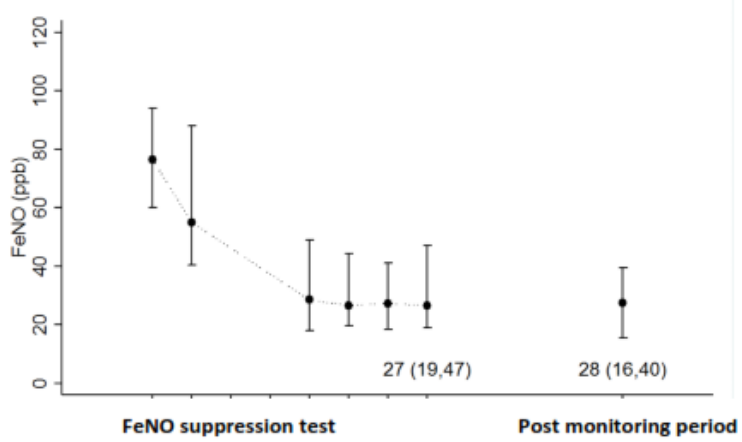

Figure 4d

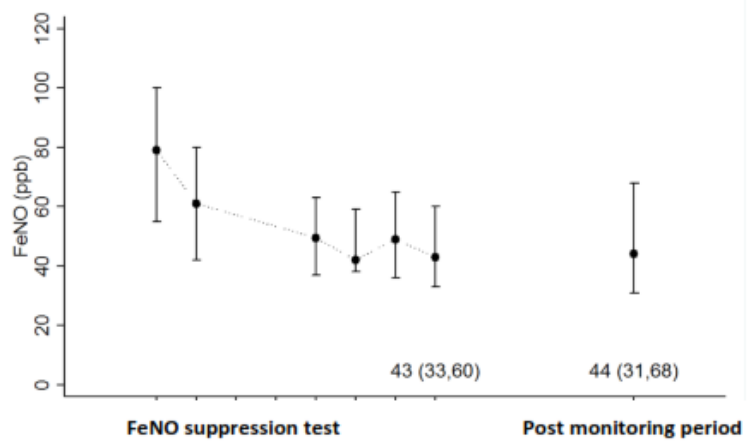


Figure 5. Blood eosinophil counts at baseline and after one month monitoring for all subjects with good adherence and (a) positive suppression test $(n=49)$ and (b) negative suppression test $(n=20)$ and for subjects, not on prednisolone and a positive suppression test (figure $5 \mathrm{c}, \mathrm{n}=24$ ) and a negative suppression test (figure $5 \mathrm{~d}, \mathrm{n}=10$ ). Insert figures are median blood eosinophil count (IQR).

\section{Figure 5a}

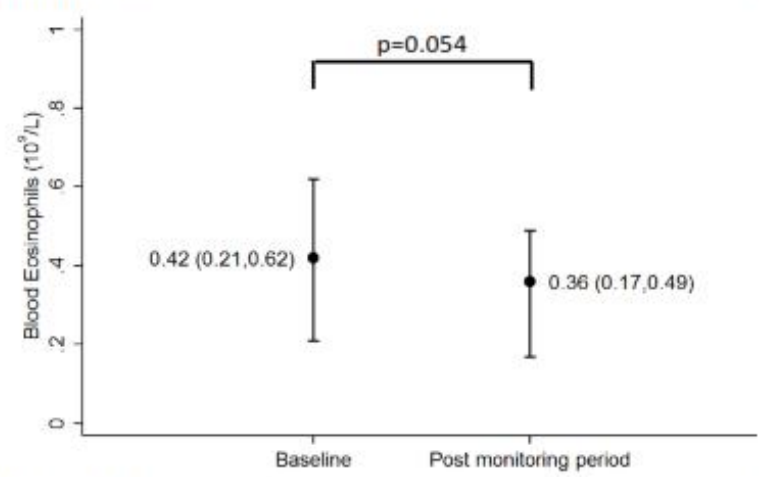

Figure 5c

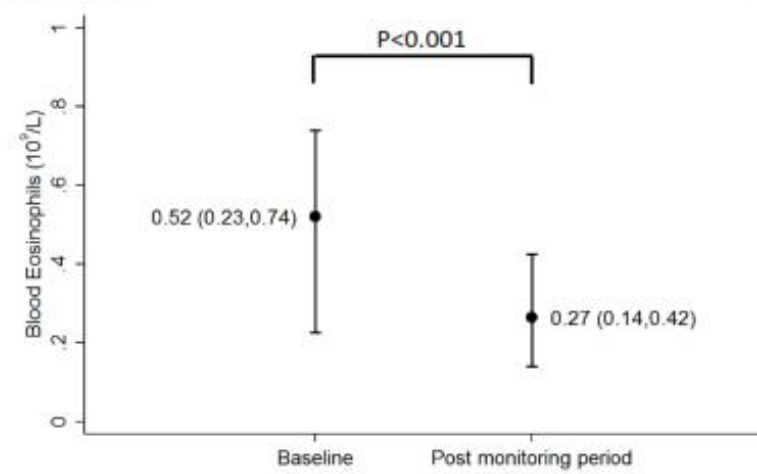

Figure 5b

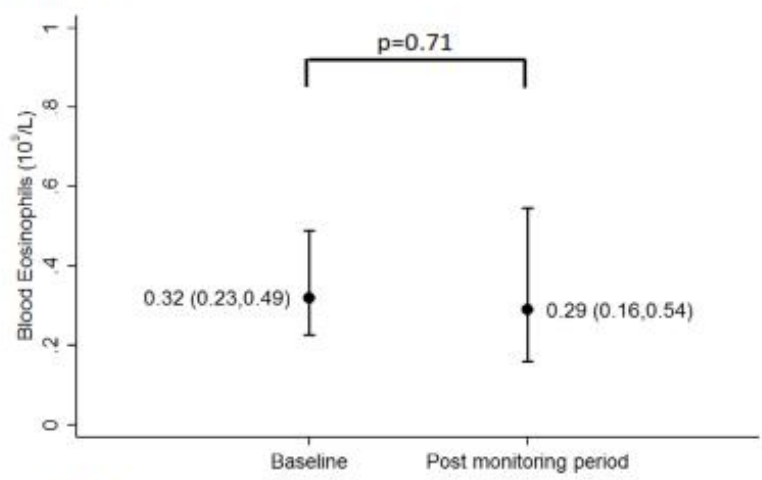

Figure 5d

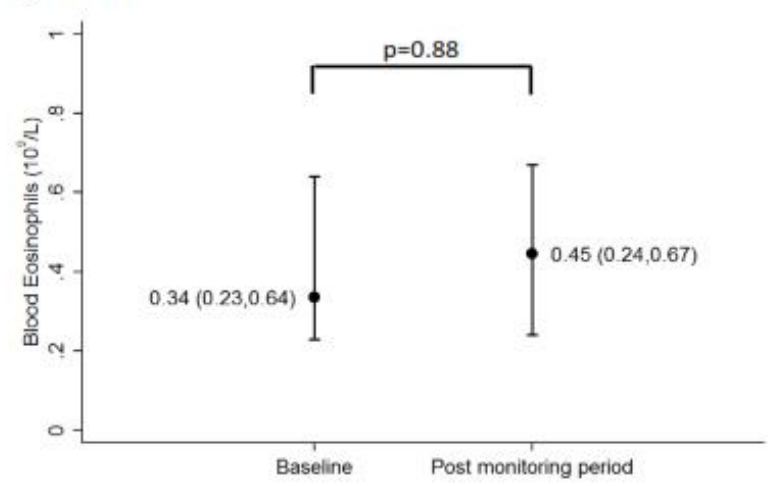


Figure 6. Correlation between Day 7 biomarkers after suppression testing with post one month monitoring values for subjects with good adherence with high dose ICS/LABA $((\geq 70 \%$ adherence with salmeterol $50 \mu \mathrm{g} / \mathrm{fluticasone} 500 \mu \mathrm{g}$ Diskus twice per day). Correlation coefficient was calculated using the Spearman's rank method (FeNO, $r=0.69 ; \mathrm{p}<0 \cdot 001$ and blood eosinophils $\mathrm{r}=0.60 ; \mathrm{p}<0 \cdot 001, \mathrm{o}=$ positive suppression test $\mathbf{\square}=$ negative suppression test).

\section{- Positive suppression - Negative suppression}
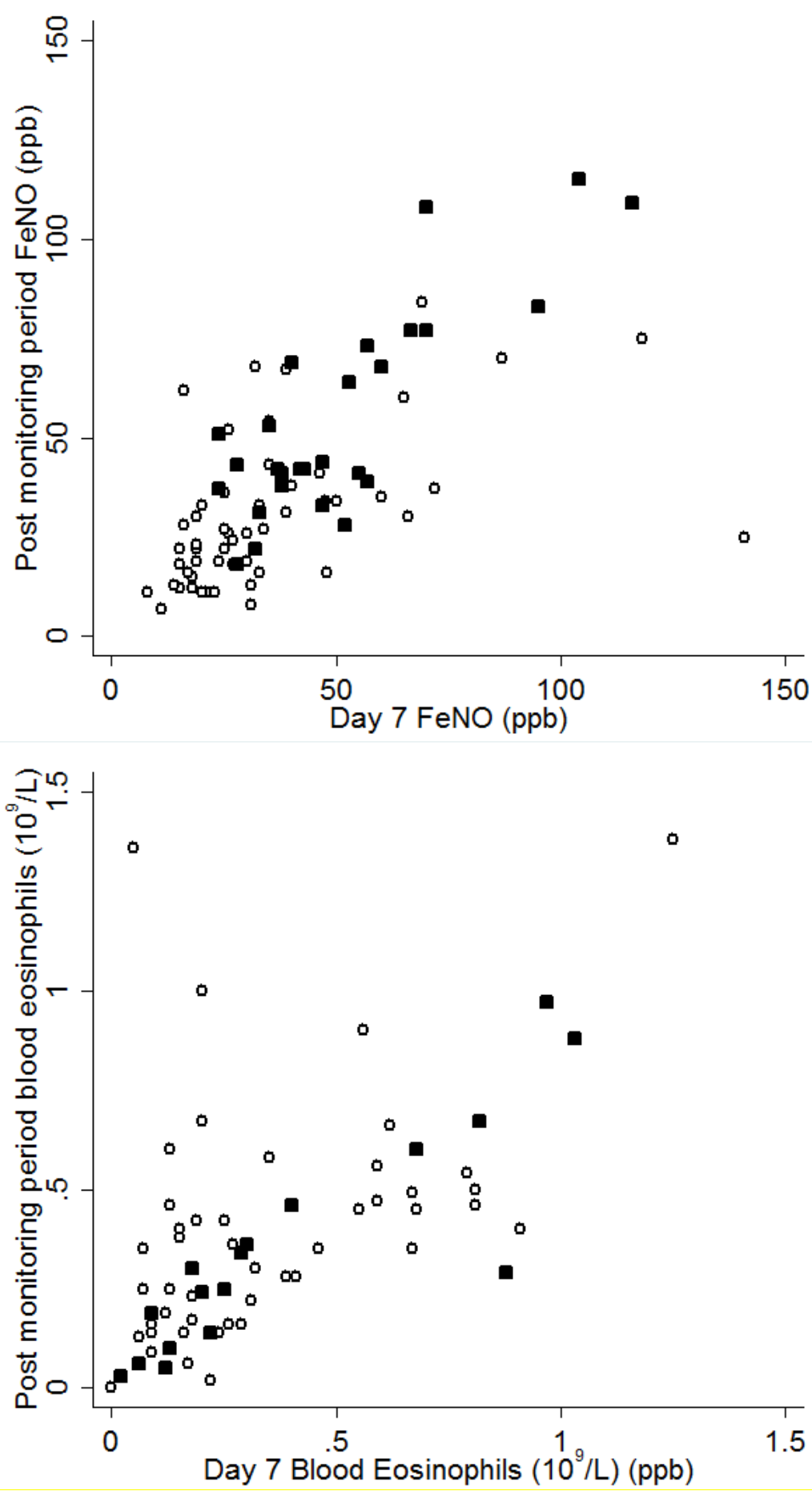


\section{Lung function and asthma symptom scores}

Lung function data and ACQ-5 scores at baseline and post one month monitoring in all subjects with good adherence are shown in Table 3. There was a significant improvement in $\mathrm{FEV}_{1}$ in those with a positive suppression test (mean difference $242 \mathrm{ml}, 95 \%$ CI 90, $395 \mathrm{ml}$, table 3 ) which was not seen in subjects with a negative suppression test (mean difference $122 \mathrm{ml}, 95 \% \mathrm{CI}-143,389 \mathrm{ml}$, table 3). There was a significant improvement in ACQ-5 in both suppressor and non-suppressor groups, which was numerically greater in subjects with a positive suppression test (mean difference $-1.2,95 \% \mathrm{CI}-0.9,-1.5)$ compared to those with a negative suppression test (mean difference $-0.9,95 \% \mathrm{CI}-0.4,-1.3)$ and there was a significant correlation between $\%$ fall in FeNO and \% improvement in ACQ-5 in all FeNO high subjects $(r=0.39, \mathrm{p}<0.001)$. For the 14 of 54 subjects with a positive FeNOSuppT and FeNO>35ppb after 1 month monitoring, there were significant improvements in FEV1\% $(81.9 \pm 20.1 \%$ to $91.9 \pm 19.2 \%, \mathrm{p}=0.05)$ and ACQ5 $(2.49 \pm 1.5$ to $1.65 \pm 0.99, \mathrm{p}<0.05)$. There was no change in ACQ-5 with monitored treatment with good adherence in subjects with initial FeNO<45ppb (table 3) and no improvement in lung function (mean difference $-114 \mathrm{ml}, 95 \% \mathrm{CI}-267,37 \mathrm{ml}$, table 3). 
Table 3. Lung function data and ACQ-5 scores and values at baseline and post one month monitoring in subjects with good adherence.

\begin{tabular}{|c|c|c|c|c|c|c|c|c|c|}
\hline & \multicolumn{3}{|c|}{$\begin{array}{l}\text { FeNO } \geq 45 p p b \text { - Positive Suppression } \\
\text { Test }(n=54)\end{array}$} & \multicolumn{3}{|c|}{$\begin{array}{l}\text { FeNO } \geq 45 p p b \text { - Negative Suppression } \\
\text { Test }(n=27)\end{array}$} & \multicolumn{3}{|c|}{ FeNO<45ppb $(n=20)$} \\
\hline & $\begin{array}{l}\text { Baseline } \\
\text { (Day 0) }\end{array}$ & $\begin{array}{l}\text { Post } \\
\text { monitoring } \\
\text { period }\end{array}$ & P value & Baseline & $\begin{array}{l}\text { Post } \\
\text { monitoring } \\
\text { period }\end{array}$ & $\begin{array}{l}P \\
\text { value }\end{array}$ & Baseline & $\begin{array}{l}\text { Post } \\
\text { monitoring } \\
\text { period }\end{array}$ & $\begin{array}{l}P \\
\text { value }\end{array}$ \\
\hline FEV $_{1}(\mathrm{~L})$ & $2.65 \pm 0.87$ & $2.89 \pm 0.82$ & 0.003 & $2.28 \pm 0.67$ & $2.40 \pm 0.78$ & 0.35 & $2.29 \pm 0.42$ & $2.18 \pm 0.42$ & 0.13 \\
\hline $\begin{array}{l}\mathrm{FEV}_{1} \% \\
\text { predicted }\end{array}$ & $80.1 \pm 16.4$ & $88.2 \pm 16.4$ & 0.001 & $70.1 \pm 16.0$ & $74.1 \pm 20.9$ & 0.30 & $74.5 .0 \pm 12.0$ & $71.0 \pm 14.5$ & 0.15 \\
\hline FVC (L) & $3.69 \pm 0.97$ & $3.88 \pm 0.98$ & $<0.001$ & $3.50 \pm 0.84$ & $3.45 \pm 0.91$ & 0.71 & $3.42 \pm 0.67$ & $3.35 \pm 0.61$ & 0.44 \\
\hline $\begin{array}{l}\text { FVC \% } \\
\text { predicted }\end{array}$ & $93.3 \pm 13.2$ & $98.1 \pm 14.0$ & $<0.001$ & $86.1 \pm 15.9$ & $85.4 \pm 19.8$ & 0.83 & $89.3 \pm 11.0$ & $87.6 \pm 10.6$ & 0.50 \\
\hline $\begin{array}{l}\mathrm{FEV}_{1} / \mathrm{FVC} \\
\text { ratio }\end{array}$ & $71.2 \pm 8.8$ & $74.7 \pm 9.1$ & 0.049 & $64.6 \pm 8.9$ & $69.2 \pm 12.5$ & 0.12 & $66.9 \pm 10.0$ & $65.2 \pm 9.9$ & 0.08 \\
\hline ACQ-5 & $2.76 \pm 1.25$ & $1.55 \pm 1.21$ & $<0.001$ & $2.81 \pm 1.61$ & $1.96 \pm 1.43$ & $<0.001$ & $1.96 \pm 1.35$ & $1.79 \pm 1.32$ & 0.32 \\
\hline
\end{tabular}

\section{Discussion}

This study demonstrates in subjects with difficult-to-control severe asthma and FeNO $\geq 45 \mathrm{ppb}, 65 \%$ had a positive FeNOsuppT and with effective adherence to LABA/ICS during a one month monitored period, there were significant improvements in both symptoms and lung function and FeNO was maintained at target levels associated with reduced exacerbation, emergency room attendances and ICU admissions ${ }^{15,16}$. In contrast, among those with a negative suppression test, there was a lesser reduction in FeNO despite taking high dose ICS/LABA efficiently, with no improvement in lung function and less improvement in symptoms.

The original description of the FeNOSuppT previously used physician directly-observed treatment (DOT) over 7 days and defined a positive FeNOsuppT for non-adherence on poor prescription filling. The remote monitoring acoustic technology in this study effectively delivers DOT by timestamping inhaler activation and analysing inhalation technique which also identifies "non- 
intentional" non-adherence, where critical inhaler errors prevent effective treatment which is known to be a common problem ${ }^{17}$. Given these patients were prescribed high dose ICS/LABA at the time of FeNOsuppT, we believe the suppression of FeNO with effectively administered ICS/LABA treatment reflects prior inefficient ICS treatment due to both intentional and non-intentional nonadherence.

In subjects with a positive FeNOsuppT, there was also a significant fall in blood eosinophil counts consistent with both biomarkers being ICS responsive when adherent with monitored treatment. Composite biomarker profiling using FeNO and blood eosinophil count allows better prognostic risk stratification with highest risk seen when both Type-2 biomarkers are high and vice versa ${ }^{18,19}$, suggesting that for subjects with a positive FeNOsuppT and resultant biomarker low profile with good adherence, there should be a parallel risk reduction for exacerbations. The longer term clinical and adherence outcomes for subjects characterised using FeNOsuppT in a severe asthma population are currently being studied (ClinicalTrials.Gov NCT02307669), but it is worth commenting that a small number of subjects, despite a good response to monitored treatment in terms of FeNO, ACQ5 and lung function improvement, have a persistent elevated peripheral blood eosinophil count. This suggests that the biological driver of blood eosinophils in these subjects may not be as ICS responsive as FeNO, and we are also currently exploring the clinical significance of this "dissociated" biomarker profile in terms of exacerbation risk and clinical outcome (ClinicalTrials.Gov NCT02717689). However, our data suggest that the biomarker profile (FeNO and blood eosinophil count) after 1 week of FeNOsuppT is closely related to the profile when taking optimised ICS/LABA treatment, thus facilitating identification of subjects where adherence intervention to optimise inhaled treatment may be of most value prior to considering treatment escalation but also potentially identifying those subjects who are likely remain biomarker high despite optimised ICS/LABA treatment and suitable for novel type 2 biologic therapies. Maximal FeNO suppression has also been shown after 7 days high dose ICS treatment in mild asthma $a^{7,20,21}$ 
and our data suggests that similar maximal suppression is seen in subjects with more severe asthma given the strong correlation between day 7 FeNO post FeNOSuppT and post monitoring FeNO. In those subjects despite having with a positive test and FeNO $>35 \mathrm{ppb}$ after monitoring, significant falls in both FeNO was seen compared to baseline with improvements in lung function and symptom scores consistent with prior ICS non-adherence and suggesting a period of optimised inhaled treatment with clinical monitoring prior to treatment escalation is appropriate.

Poor-adherence is common in subjects with severe asthma ${ }^{1.2,3}$. The availability of novel biologic therapies targeting type-2 cytokines makes identification of sub-optimal adherence to ICS important so that these issues can be explored prior to treatment escalation. An attractive proposition is to move away from using imperfect surrogate measures of adherence (e.g. patient self-report, physician impression, prescription records) to using an ICS responsive biomarker (FeNO) as part of a clinical phenotyping strategy and precision medicine delivery. The FeNO-low group $(\mathrm{FeNO}<45 \mathrm{ppb})$ demonstrate a small reduction in FeNO with monitored optimised treatment with ICS/LABA with a FeNO in a similar range to those subjects with a positive suppression test and optimised treatment. There was no change in peripheral blood eosinophil count, ACQ-5 or lung function, which may reflect the fact that this low FeNO group are more adherent to background ICS treatment and the potential for further clinical improvement with optimised ICS/LABA in this FeNO-low group is less.

A strength of this data is that it occurred in a "real world" setting, by-passing the challenging aspect of engaging a non-adherent difficult-to-control asthma population in a clinical trial ${ }^{22}$. As well as providing insight into ICS therapeutic response in a short period of time, this approach identifies subjects who can use a particular inhaler efficiently and wish to engage with a monitoring strategy to assist them with their inhaler use. However, it is worth emphasising that 70 of 169 subjects [41\%] failed to take $\geq 70 \%$ or complete 1 month monitoring of inhaled treatment despite being 
proficient in inhaler use and keen for support, suggesting there are barriers to even short-term use of technological support to assist with inhaled treatment adherence. If these barriers could be identified and addressed, there could be substantial gains with optimised use of high dose ICS/LABA treatment in this poorly controlled, high-risk asthma population, however defining the best intervention to change non-adherent behaviour is outwith the scope of this study. Only 16 patients were unable or forgot to perform daily FeNO during the 7-day home assessment suggesting that this is not a major barrier to home delivery of domiciliary FeNOSuppT, however inadequate use of the monitored ICS was more common.

Formal cost-effectiveness analysis of 'biomarker-based' assessments with adherence monitoring is also required, however this seems likely by identifying subjects who may achieve adequate asthma control without the need for treatment escalation to expensive biologic agents. Subjects with a positive FeNOSuppT were younger with more eczema and higher IgE suggesting greater ICS responsiveness in this group though hospital admissions were equally prevalent in the high FeNO group with positive and negative suppression tests. In the National Heart, Lung, and Blood Institute Severe Asthma Research Program, a high FeNO (>35ppb) was associated with greater emergency room visits and hospital and ICU admissions and again in a younger, more atopic patient cohort ${ }^{15}$. If adherence could be satisfactorily addressed in this ICS responsive FeNO high difficult-to-control asthma population, there could potentially be a substantial impact on hospital admission rates.

In summary, we have demonstrated that and FeNOsuppT can be delivered using remote monitoring technology in routine clinical care in specialist severe asthma services in the UK. Short-term profiling of the FeNO response to ICS exposure in subjects with difficult-to-control severe asthma is a helpful part of clinical phenotyping to identify those who are likely to respond better to high dose ICS/LABA therapy when used regularly and those who, despite good adherence with inhaled treatment, are likely to require additional treatment. In addition, aligning monitoring of ICS 
treatment with FeNO response may be of value in identifying ICS responsive subjects prior to recruitment to clinical trials investigating interventions which are "add-on" treatments to standard care (ICS/LABA) and also to studies investigating "true" ICS resistant disease. Future studies are required to identify the optimal intervention to maintain ongoing adherence in a difficult-to-control severe asthma population, but understanding the potential therapeutic benefit in an individual patient is a useful part of routine care. 


\section{References}

1. Gamble J, Stevenson M, McClean E, Heaney LG. The prevalence of nonadherence in difficult asthma. Am J Respir Crit Care Med 2009; 180: 817-822.

2. Murphy AC, Proeschal A, Brightling CE, Wardlaw AJ, Pavord I, Bradding P, Green RH. The relationship between clinical outcomes and medication adherence in difficult-to-control asthma. Thorax. 2012 Aug; 67:751-3.

3. Hekking PP, Wener RR, Amelink M, Zwinderman AH, Bouvy ML, Bel EH. The prevalence of severe refractory asthma. J Allergy Clin Immunol. 2015 Apr; 135: 896-902.

4. Medicines Adherence. Involving Patients in Decisions about Prescribed Medicines and Supporting Adherence. NICE Clinical Guidelines, No. 76. National Collaborating Centre for Primary Care (UK). London: Royal College of General Practitioners (UK); 2009 Jan.

5. Lindsay JT, Heaney LG. Non-adherence in difficult asthma and advances in detection. Expert Rev Respir Med. 2013 Dec; 7:607-14.

6. Smith AD, Cowan JO, Brassett KP, Filsell S, McLachlan C, Monti-Sheehan G, Peter Herbison G, Robin Taylor D.. Exhaled nitric oxide a predictor of steroid response. Am J Respir Crit Care Med 2005; 184:602-615.

7. Mehta V, Stokes JR, Berro A, Romero FA, Casale TB. Time-dependent effects of inhaled corticosteroids on lung function, bronchial hyperresponsiveness, and airway inflammation in asthma. Ann Allergy Asthma Immunol. 2009 Jul; 103:31-7.

8. Silkoff PE, McClean P, Spino M, Erlich L, Slutsky AS, Zamel N. Dose-response relationship and reproducibility of the fall in exhaled nitric oxide after inhaled beclomethasone dipropionate therapy in asthma patients. Chest. 2001; 119: 1322-8.

9. McNicholl DM, Stevenson M, McGarvey LP, Heaney LG. The utility of fractional exhaled nitric oxide suppression in the identification of nonadherence in difficult asthma. Am J Respir Crit Care Med. 2012; 186:1102-8. 
10. Kupczyk M, Brinke AT, Sterk PJ, Bel EH, Papi A, Chanez P, Nizankowska-Mogilnicka E, Gjomarkaj M, Gaga M, Brusselle G, Dahlén B, Dahlén SE; BIOAIR investigators. Frequent exacerbators: a distinct phenotype of severe asthma. Clin Exp Allergy 2014; 44: 212-221.

11. Dweik RA, Boggs PB, Erzurum SC, Irvin CG, Leigh MW, Lundberg JO, Olin AC, Plummer AL, Taylor DR; American Thoracic Society Committee on Interpretation of Exhaled Nitric Oxide Levels (FENO) for Clinical Applications. An Official ATS Clinical Practice Guideline: Interpretation of Exhaled Nitric Oxide Levels (FeNO) for Clinical Applications. Am J Respir Crit Care Med 2011; 184:602-615.

12. Hetherington KJ, Costello RW and Heaney LG. S2 Fractional exhaled nitric oxide (FeNO) suppression to identify non-adherence in difficult asthma. Thorax 2016; 71(3): A4-A5.

13. Heaney LG, Djukanovic R, Woodcock A, Woodcock A, Walker S, Matthews JG, Pavord ID, Bradding P, Niven R, Brightling CE, Chaudhuri R, Arron JR, Choy DF, Cowan D, Mansur A, Menzies-Gow A, Adcock I, Chung KF, Corrigan C, Coyle P, Harrison T, Johnston S, Howarth P, Lordan J, Sabroe I, Bigler J, Smith D, Catley M, May R, Pierre L, Stevenson C, Crater G, Keane F, Costello RW, Hudson V, Supple D, Hardman T. Research in progress: Medical Research Council United Kingdom Refractory Asthma Stratification Programme (RASP-UK). Thorax. 2015; 71:187.

14. Sulaiman I, Greene G, MacHale E, Seheult J, Mokoka M, D'Arcy S, Taylor T, Murphy DM, Hunt E, Lane SJ, Diette GB, FitzGerald JM, Boland F, Sartini Bhreathnach A, Cushen B, Reilly RB, Doyle F, Costello RW. A randomised clinical trial of feedback on inhaler adherence and technique in patients with severe uncontrolled asthma. Eur Respir J. 2018 Jan 4;51(1). pii: 1701126. doi: 10.1183/13993003.01126-2017.

15. Dweik RA, Sorkness RL, Wenzel S, Hammel J, Curran-Everett D, Comhair SA, Bleecker E, Busse W, Calhoun WJ, Castro M, Chung KF, Israel E, Jarjour N, Moore W, Peters S, Teague G, Gaston B, Erzurum SC; National Heart, Lung, and Blood Institute Severe Asthma Research Program. Use of exhaled nitric oxide measurement to identify a reactive, 
at-risk phenotype among patients with asthma. Am J Respir Crit Care Med. 2010 May $15 ; 181(10): 1033-41$

16. Petsky HL, Kew KM, Turner C, Chang AB. Exhaled nitric oxide levels to guide treatment for adults with asthma. Cochrane Database Syst Rev. 2016 Sep 1; 9:CD011440. [Epub ahead of print].

17. Peter Daley-Yates, Amanda Baines, Kylie Riddell, Shashidhar Joshi, Philippe Jean Bareille, George Bardsley, Richard Beasley, James Fingleton. European Respiratory Journal 2017 50: OA276; DOI: 10.1183/1393003.congress-2017.OA276.

18. Malinovschi A, Janson C, Borres M, Alving K. Simultaneously increased fraction of exhaled nitric oxide levels and blood eosinophil counts relate to increased asthma morbidity. J Allergy Clin Immunol. 2016 Nov;138(5):1301-1308.

19. Malinovschi A, Fonseca JA, Jacinto T, Alving K, Janson C. Exhaled nitric oxide levels and blood eosinophil counts independently associate with wheeze and asthma events in National Health and Nutrition Examination Survey subjects. J Allergy Clin Immunol. 2013 Oct;132(4):821-7

20. Kharitonov SA, Donnelly LE, Montuschi P, Corradi M, Collins JV, Barnes PJ. Dosedependent onset and cessation of action of inhaled budesonide on exhaled nitric oxide and symptoms in mild asthma. Thorax. 2002 Oct;57(10):889-96

21. Lavorini F, Magnan A, Dubus JC, Voshaar T, Corbetta L, Broeders M, Dekhuijzen R, Sanchis J, Viejo JL, Barnes P, Corrigan C, Levy M, Crompton GK. Effect of incorrect use of dry powder inhalers on management of patients with asthma and COPD. Respir Med. 2008 Apr;102(4):593-604.

22. Gamble J, Stevenson M, Heaney LG. A study of a multi-level intervention to improve non-adherence in difficult to control asthma. Respir Med. 2011 Sep; 105:1308-15. 


\section{Acknowledgements}

This study was part of the Medical Research Council UK Refractory Asthma Stratification

Programme and programme support was obtained from Aerocrine AB (FeNO measurement) and Vitalograph (INCA monitoring system) within that Consortium. We are grateful to Kathy Hetherington for assistance in project support and the medical teams who helped integrate these tests into their clinical practice, in particular:

Belfast Health \& Social Care Trust - Dr Claire A Butler, Dr Jacqui Gamble, Kirsty Honeyford Oxford University Hospitals NHS Trust - Luisa Vaz Batista, Claire Connolly, Katie Borg Glenfield Hospital, University Hospitals of Leicester NHS Trust - Michelle Craner, Claire Boddy Wythenshawe Hospital, University Hospitals of South Manchester NHS Trust - Leanne-Jo Homes Gartnavel General and Glasgow Royal Infirmary Hospitals, Greater Glasgow Health Board - Dr Douglas Cowan, Dr Jieqiong Freda Yang, Diane Murray, Femke Steffenson Heartlands Hospital, Heart of England NHS Foundation Trust - Verity Mitchell 
Remotely monitored therapy and nitric oxide suppression identifies non-adherence in severe asthma

Liam G Heaney, John Busby, Peter Bradding, Rekha Chaudhuri, Adel H Mansur, Robert Niven, Ian D Pavord, John T Lindsay and Richard W Costello on behalf of the Medical Research Council UK Refractory Asthma Stratification Programme (RASP-UK).

\section{Online Data Supplement}


Clinical services approached to implement the remote monitoring technology

Belfast Health \& Social Care Trust*

Oxford University Hospitals NHS Trust*

Glenfield Hospital, University Hospitals of Leicester NHS Trust**

Wythenshawe Hospital, University Hospitals of South Manchester NHS Trust*

Gartnavel General Hospital, Greater Glasgow \& Clyde Health Board*

Heartlands Hospital, Heart of England NHS Foundation Trust*

Stobhill/Glasgow Royal Infirmary Hospital, Greater Glasgow \& Clyde Health Board**

University College London Hospital, University College London Hospitals NHS Foundation

Trust**

Royal Brompton \& Harefield NHS Foundation Hospital***

Freemans Hospital, Newcastle upon Tyne NHS Foundation Trust

University Hospital Southampton NHS Foundation Trust

Nottingham University Hospitals NHS Foundation Trust

* Clinical centres using FeNO suppression and remote monitoring technology contributing to data in manuscript

** Clinical centres subsequently using FeNO suppression and remote monitoring technology

*** Clinical centre using FeNO suppression in-patient assessment 


\section{Supplementary Methods}

Acoustic Monitoring Technology

The INCA ${ }^{\mathrm{TM}}$ device is attached to the Accuhaler and a microphone is activated when the device is opened and stops when the inhaler device is closed (Figure e1). If the inhaler device is left open, the recoding automatically shuts off after 90 seconds.

The INCA ${ }^{\mathrm{TM}}$ Analysis software processes the sound files generated by the INCA ${ }^{\mathrm{TM}}$ device to assess if the inhaler has been taken properly (Figure e2). Most of the inhalations during the service evaluation were deemed satisfactory by the software and any "technique errors" identified by the software, were subsequently manually over-read by the clinical team.

Feedback from the 7 day Flixotide Accuhaler technique and usage (Figure e3) during the FeNO suppression testing was also examined to ensure that patients could use the Accuhaler device efficiently. If this was the case and patients wished to continue to use the technology to assist with their inhaled treatment, they were then provided with a salmeterol $50 \mu \mathrm{g} /$ fluticasone $500 \mu \mathrm{g}$ Accuhaler with INCA ${ }^{\mathrm{TM}}$ device to be taken once in the morning and once in the evening (standard high dose ICS/LABA therapy) and again instructed in inhaler use. On return to the clinic, the data was uploaded and an easily interpretable readout was produced for the clinician to provide further feedback to the patient (figure e4).

\section{Positive FeNO suppression test}

A positive FeNO suppression test was defined as previously with a Lg10 $\Delta$ FeNO greater than or equal to 0.24 where $\operatorname{Lg} 10 \Delta$ FeNO was calculated as $\{$ mean (Lg10 FeNO Day0, Lg10FeNODay 1) $\}$ $\{$ mean(Lg10 FeNO Day 4, Lg10 FeNO Day 5) $\}$. In effect, a $42 \%$ fall in FENO between the Day 0/Day 1 and the Day 4/Day 5 mean values equates with a positive suppression test. 
Figure e1. INCA ${ }^{\mathrm{TM}}$ device which is attached to Accuhaler inhaler.

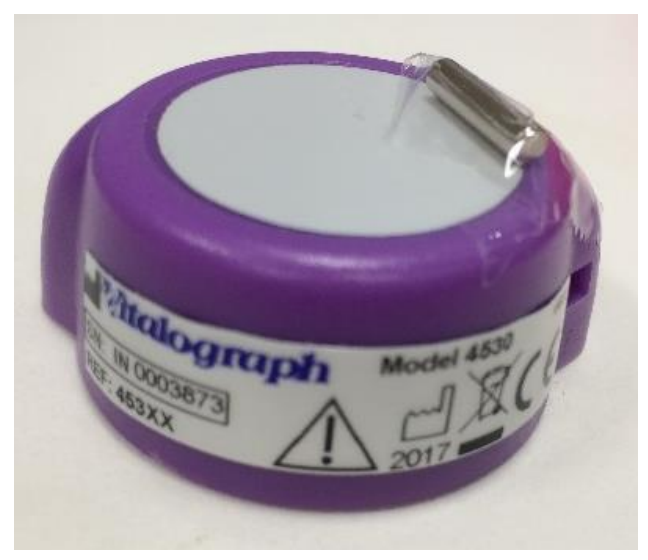

Figure e2. Example of sound file and semi-automated analysis

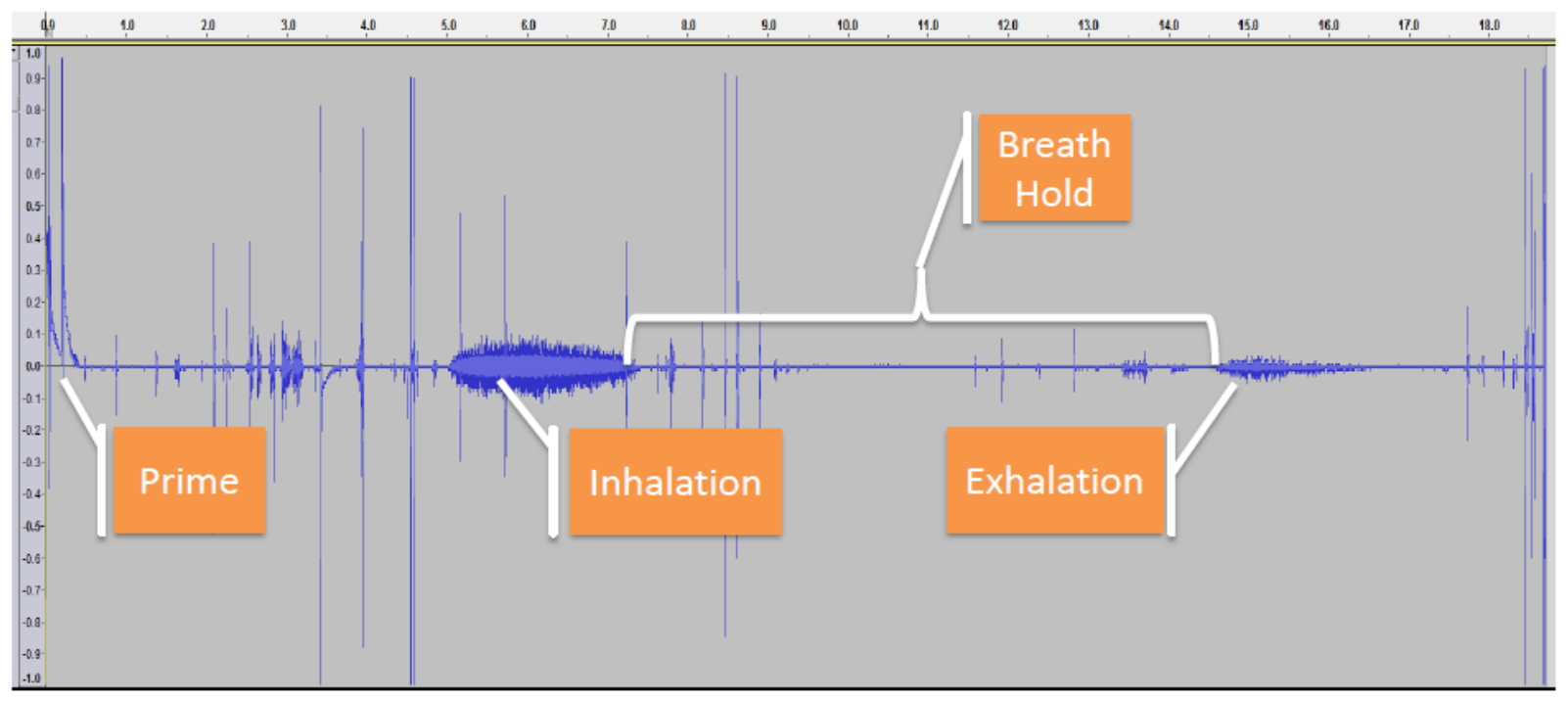


Figure e3. Data from the Vitalograph server following upload of one week FeNO suppression data and INCA ${ }^{\mathrm{TM}}$. The Vitalograph server shows activation and usage of both FeNO machine and INCA $^{\mathrm{TM}}$ device (figure e3A) and depicts the FeNO data as precentage change from baseline as originally described (y1-aixs figure A). The INCA ${ }^{\mathrm{TM}}$ device time and date stamps the number of inhaler uses (y2-axis - Figure A) and this is shown alongside technique analysis (figure e3B). Possible technique errors which can be indentified and reported are shown in Graphic 3.

\section{Figure e3A}
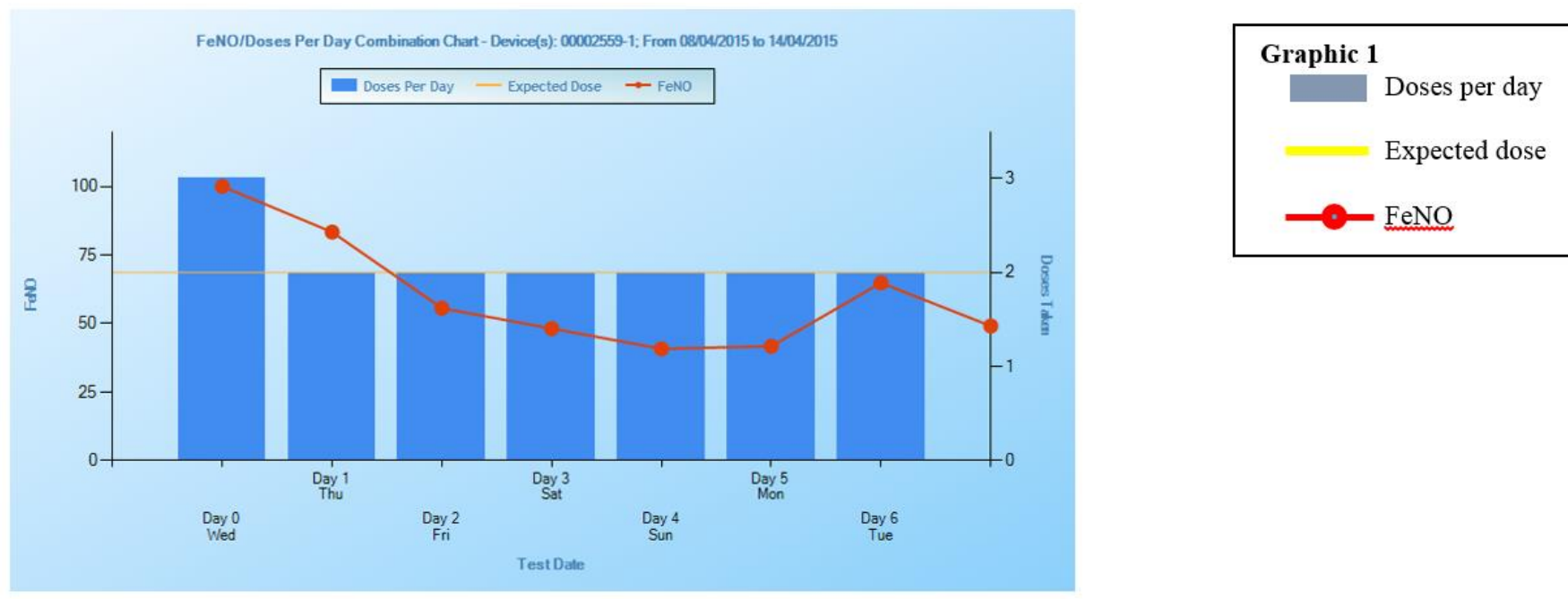

\section{Figure e3B}

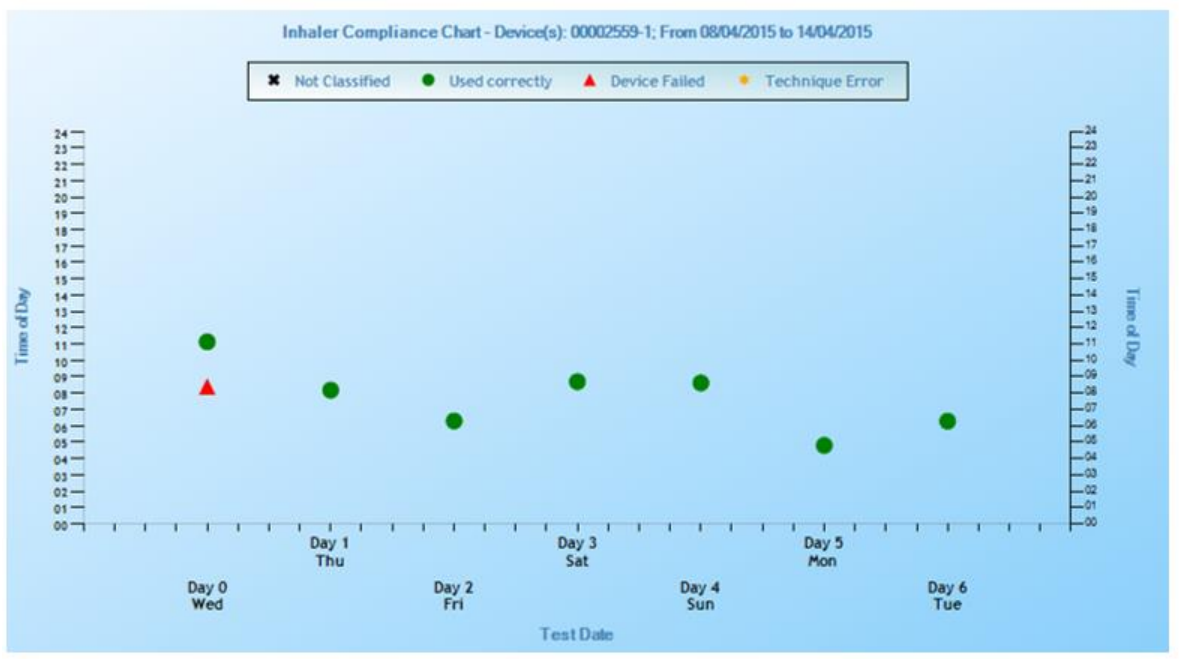

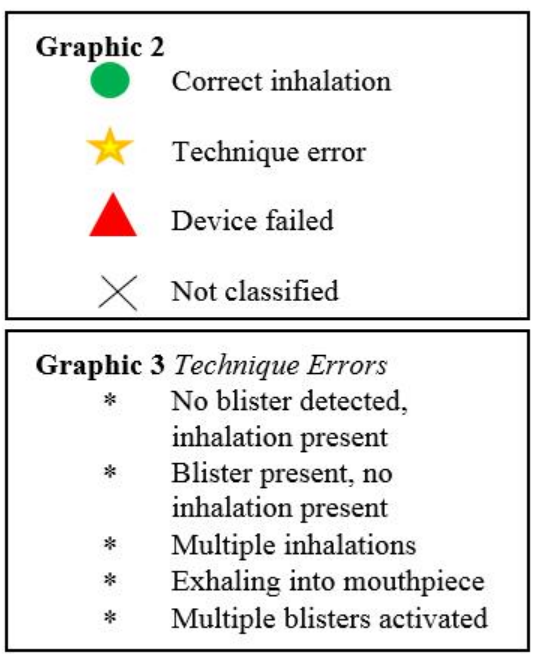


Figure e4. Data from the Vitalograph server following upload of one month salmeterol $50 \mu \mathrm{g} /$ fluticasone $500 \mu \mathrm{g}$ Accuhaler bd INCA ${ }^{\mathrm{TM}}$ soundfiles. The Vitalograph server shows usage of the INCA ${ }^{\mathrm{TM}}$ device which time and date stamps the number of inhaler uses (A) and technique analysis (B). Possible technique errors which can be indentified and reported are shown in the graphic in figure e3.

\section{Figure e4A}

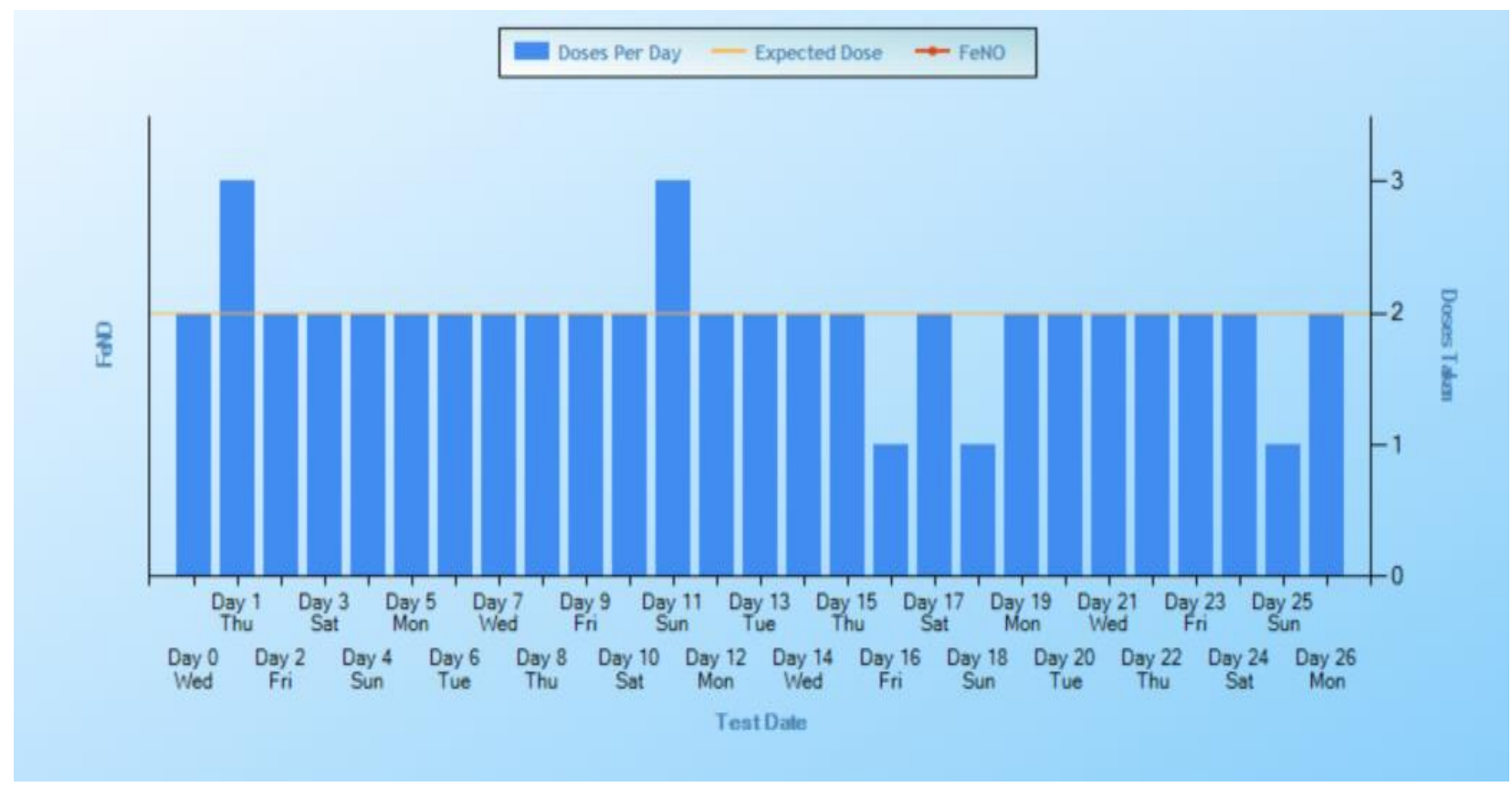

\section{Figure e4B}




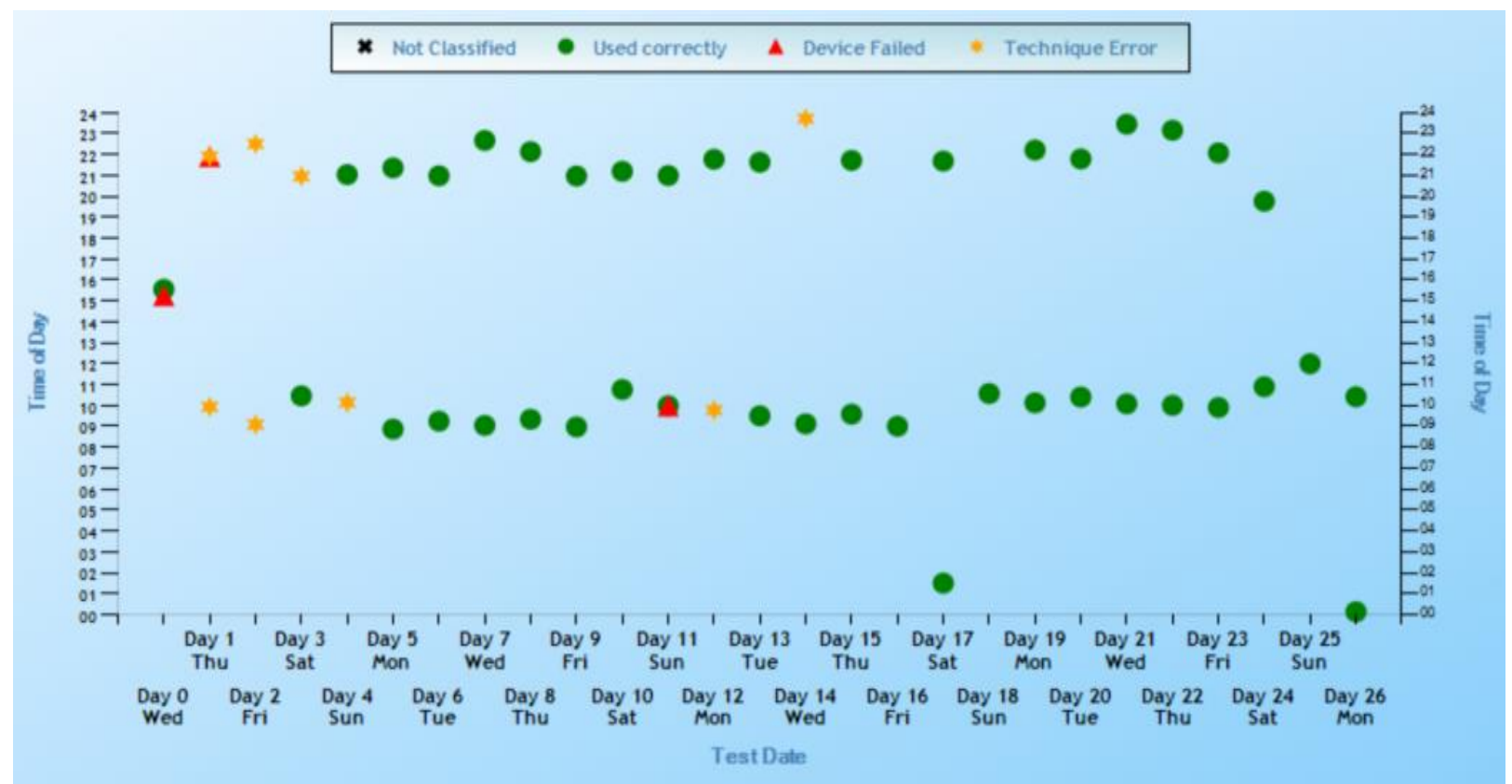




\section{Supplementary Results}

Table e1. Baseline patient characteristics of the 290 patients attending severe asthma clinics due to poor asthma control. Patients with FeNO $\geq 45 \mathrm{ppb}$ (multicentre high FeNO group, $\mathrm{n}=250$ ) had FeNO suppression testing and patients with FeNO $<45 \mathrm{ppb}$ (single centre low FeNO group, $\mathrm{n}=40$ ). Data are shown as median (IQR), mean (SD) or $\mathrm{n}(\%)$ as appropriate

\begin{tabular}{|c|c|c|c|}
\hline & FeNo High $(n=250)$ & FeNO Low $(n=40)$ & $P$ value \\
\hline Female, n (\%) & $147(58.8 \%)$ & $30(75.0 \%)$ & 0.051 \\
\hline Age, (years) & $43.6(15.9)$ & $46.5(12.6)$ & 0.279 \\
\hline Smoking, n (\%) & & & 0.151 \\
\hline Never smoked & $194(77.6 \%)$ & 26 (65.0\%) & \\
\hline Ex-smoker & 49 (19.6\%) & $13(32.5 \%)$ & \\
\hline Current smoker & $3(1.2 \%)$ & $1(2.5 \%)$ & \\
\hline \multicolumn{4}{|l|}{ Data not available $(n=4)$} \\
\hline Atopic, $n(\%)^{a}$ & $146(58.4 \%)$ & $20(50.0 \%)$ & 0.230 \\
\hline Data not available & $7(2.8 \%)$ & 0 (0.0\%) & \\
\hline ACQ-5 & $2.8(1.4)$ & $2.6(1.4)$ & 0.314 \\
\hline FeNO (ppb) & $81(58,114)$ & $28(14,36)$ & $<0.001$ \\
\hline Eosinophils (cells $\times 10^{9} / \mathrm{L}$ ) & $0.41(0.23,0.69)$ & $0.24(0.10,0.50)$ & 0.006 \\
\hline Inhaled steroid (BDP equivalent $\mu \mathrm{g})^{\mathrm{b}}$ & $1701(683)$ & $1642(400)$ & 0.606 \\
\hline $\begin{array}{l}\text { On maintenance prednisolone; } \mathbf{n}(\%) \\
\text { Data not available }(n=1)\end{array}$ & $130(52.0 \%)$ & $23(57.5 \%)$ & 0.534 \\
\hline Prednisolone dose $(\mathrm{mg}) ;$ Mean \pm SD & $11.7(7.1)$ & $10.6(5.5)$ & 0.470 \\
\hline Hospital admission past 12 months; n (\%) & & & 0.095 \\
\hline 0 & $167(66.8 \%)$ & $25(62.5 \%)$ & \\
\hline 1 & $37(14.8 \%)$ & $12(30.0 \%)$ & \\
\hline 2 & $14(5.6 \%)$ & $1(2.5 \%)$ & \\
\hline $3+$ & $26(10.4 \%)$ & $2(5.0 \%)$ & \\
\hline \multirow{2}{*}{\multicolumn{4}{|c|}{$\begin{array}{l}\text { Data not available }(n=6) \\
\text { Unscheduled attendance with asthma (GP or }\end{array}$}} \\
\hline & & & \\
\hline ER) past 12 months; median (IQR) & $3(0,5)$ & $4(2,10)$ & 0.043 \\
\hline $\begin{array}{l}\text { Ever admitted to an Intensive Care Unit; } \mathbf{n}(\%) \\
\text { Data not available }(n=6)\end{array}$ & $30(12.0 \%)$ & $3(7.5 \%)$ & 0.380 \\
\hline $\begin{array}{l}\text { Ever invasive ventilation; } \mathbf{n}(\%) \\
\text { Data not available }(\mathrm{n}=17)\end{array}$ & $15(6.0 \%)$ & $2(5.0 \%)$ & 0.728 \\
\hline $\begin{array}{l}\text { Eczema; } \mathbf{n}(\%) \\
\quad \text { Data not available }(n=26)\end{array}$ & $37(14.8 \%)$ & $6(15.0 \%)$ & 0.811 \\
\hline $\begin{array}{l}\text { Nasal polyps; } \boldsymbol{n}(\%) \\
\quad \text { Data not available }(n=29)\end{array}$ & $65(26.0 \%)$ & $12(30.0 \%)$ & 0.940 \\
\hline $\mathrm{FEV}_{1}(\%) ;$ Mean \pm SD & $72.9(20.2)$ & 75.6 (19.9) & 0.464 \\
\hline FVC (\%); Mean \pm SD & $89.1(19.1)$ & $90.0(18.1)$ & 0.789 \\
\hline $\mathrm{FEV}_{1} / \mathrm{FVC}(\%) ;$ Mean \pm SD & $67.5(12.5)$ & $67.3(11.6)$ & 0.917 \\
\hline IgE (kU/L); Median (IQR) & $182(74,616)$ & $108(48,303)$ & 0.163 \\
\hline
\end{tabular}

$a=$ atopy defined with immunology test; skin prick or RAST positive to inhaled perennial allergen (cat, dog, house dust mite, mixed grasses) $b=$ baseline dose of inhaled steroid as prescribed are equivalent dose of beclomethasone dipropionate (BDP) 
Figure e5. FeNO suppression curves (shown as \% of baseline) for subjects with initial FeNO $\geq 45$ $\mathrm{ppb}$ and a positive suppression test (figure $\mathrm{e} 5 \mathrm{a}, \mathrm{n}=130$ ) and a negative suppression test (figure $\mathrm{e} 5 \mathrm{~b}$, $\mathrm{n}=71$ ). Insert figures are median \% of baseline FeNO (IQR).

\section{Figure e5a}

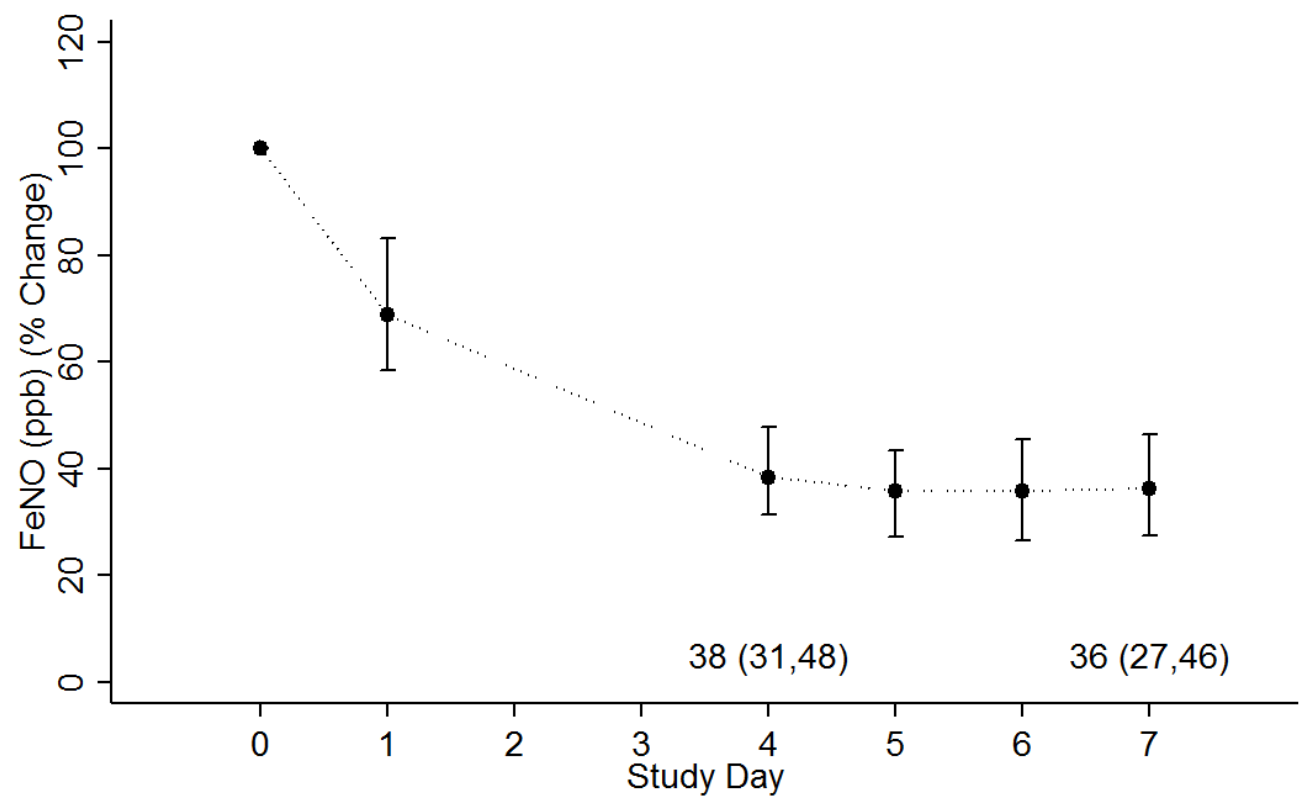

\section{Figure e5b}

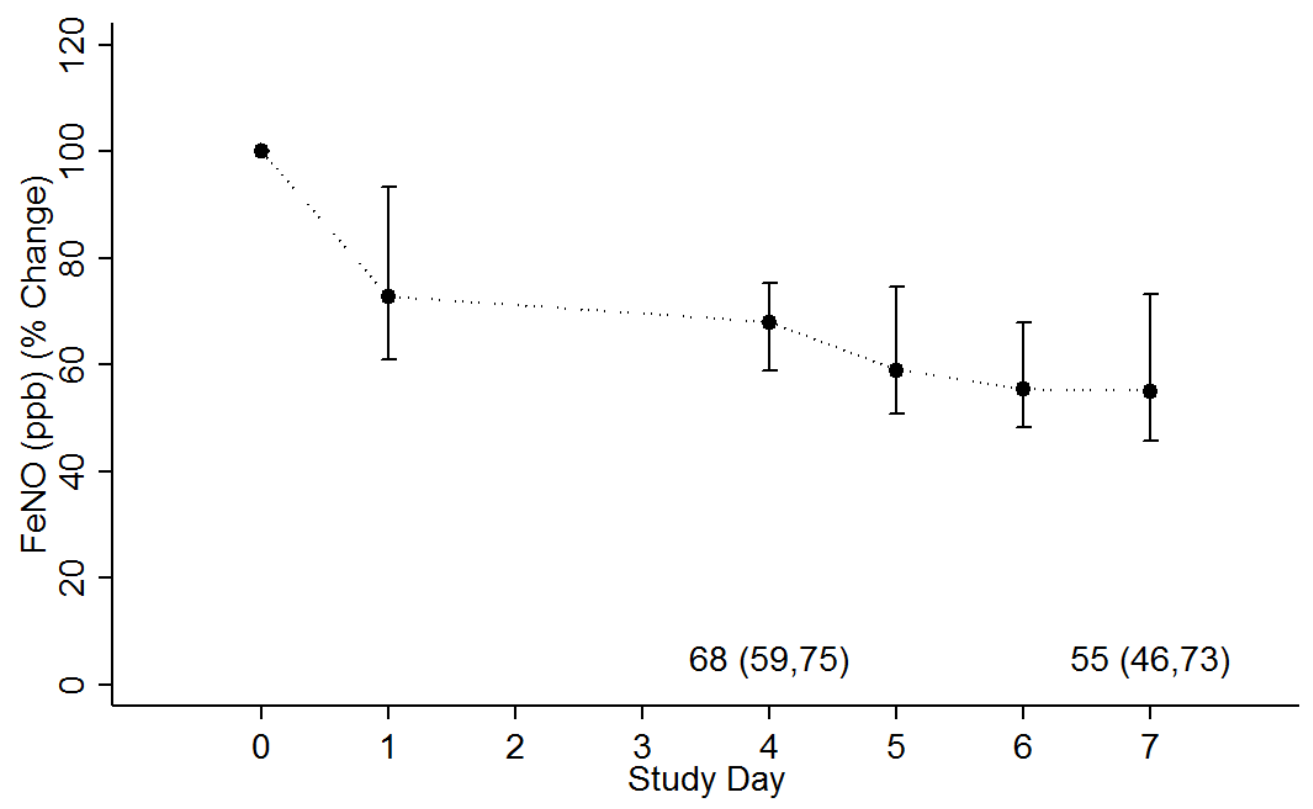


Figure e6. FeNO suppression curves (shown as median values, IQR) for subjects on maintenance prednisolone with initial $\mathrm{FeNO} \geq 45 \mathrm{ppb}$ and a positive suppression test (figure e6a, $\mathrm{n}=61$ ) and a negative suppression test (figure e6b, n=45). Insert figures are median FeNO (IQR) for Day 0, 4 and 7).

\section{Figure e6a}

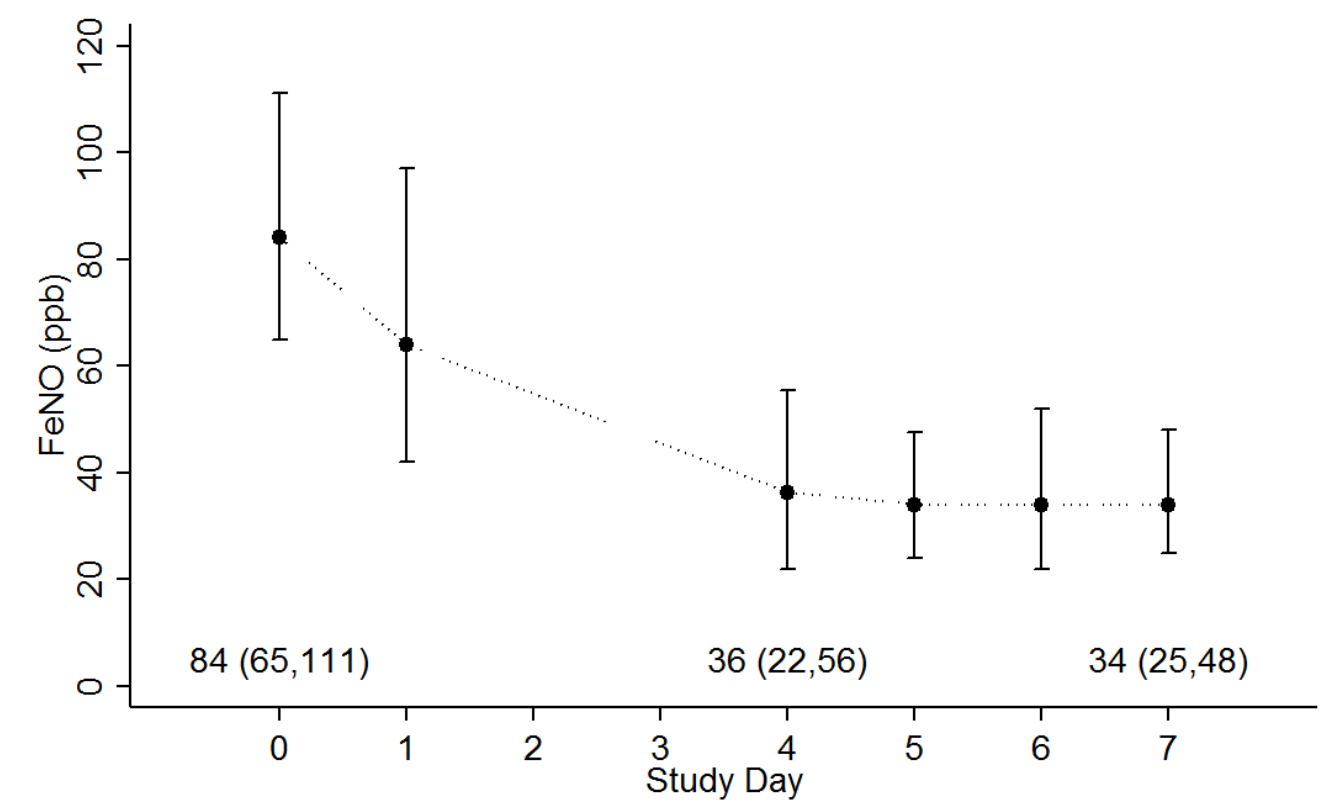

\section{Figure e6b}

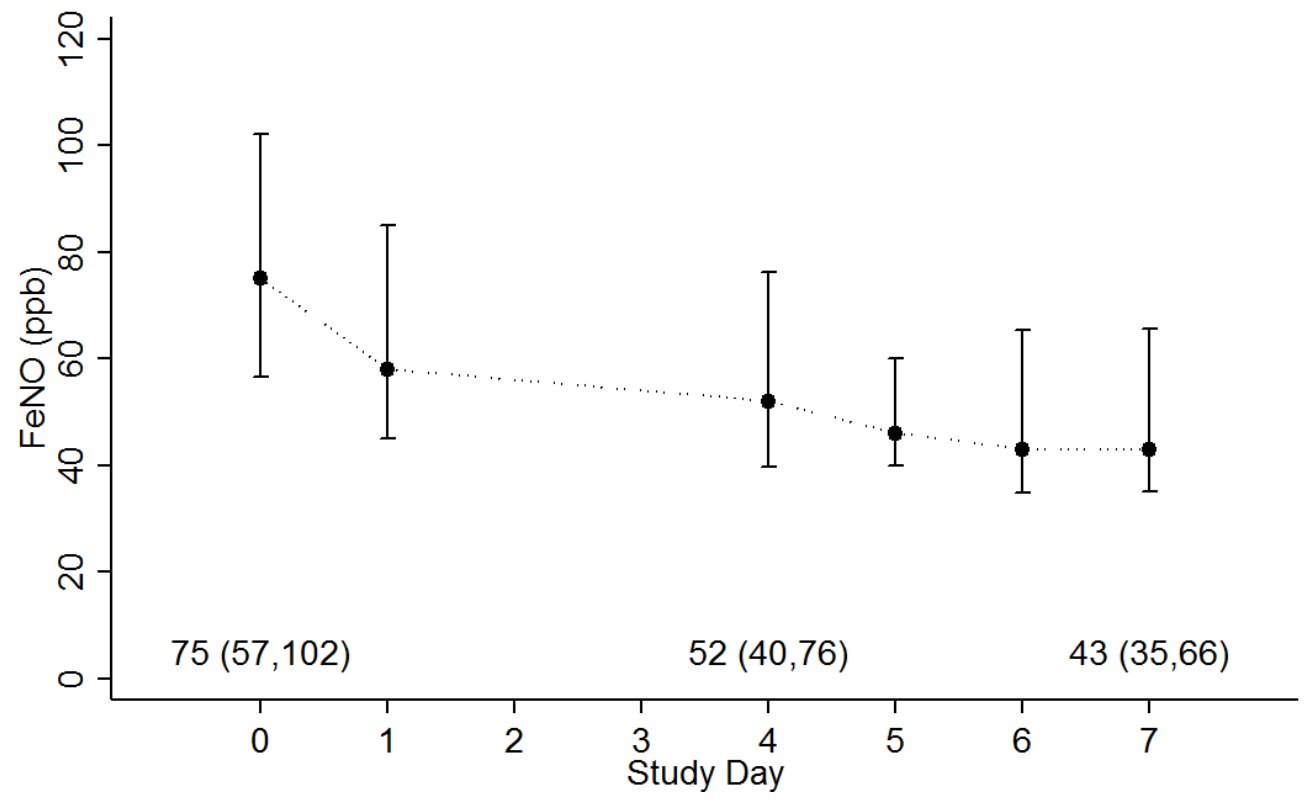




\section{Receiver Operator Characteristic analysis}

We used ROC analysis to examine the predictive value of a positive suppression test for the FeNO level at the end of the one month monitoring period in patients with good adherence with high dose ICS/LABA ( $\geq 70 \%$ salmeterol $50 \mu \mathrm{g} /$ fluticasone $500 \mu \mathrm{g}$ Accuhaler one inhalation twice per day) (Figure e7). The area under the curve was $0.81(95 \%$ CI, 0.72-0.91) and the best cut point for specificity and sensitivity using the formula $d=\sqrt{ }\left[(1-\mathrm{sn})^{2}+(1-\mathrm{sp})^{2}\right]$ was FeNO $35 \mathrm{ppb}$. The sensitivity of a positive FeNO suppression test for post monitoring FeNO $\leq 35 \mathrm{ppb}$ when adherent with treatment was $89 \%(95 \%$ CI, 76 - 96\%) and specificity 61\% (95\% CI, $44-77 \%)$. In terms of predictive value, 40 of 54 positive tests had a post one month monitoring FeNO $\leq 35 \mathrm{ppb}$ and 22 of

27 negative tests had a FeNO $>35 \mathrm{ppb}$ giving a positive predictive value for a FeNO $\leq 35 \mathrm{ppb}$ of $74 \%$ [95\% CI, $65-81 \%$ ] and a negative predictive value of $82 \%$ [95\% CI, $65-91 \%$ ]. 
Figure e7 ROC analysis examining the predictive value of a positive suppression test for one month post monitoring FeNO in those patients with good adherence with high dose ICS/LABA $((\geq 70 \%$ salmeterol $50 \mu \mathrm{g} /$ fluticasone $500 \mu \mathrm{g}$ Accuhaler one inhalation twice per day).

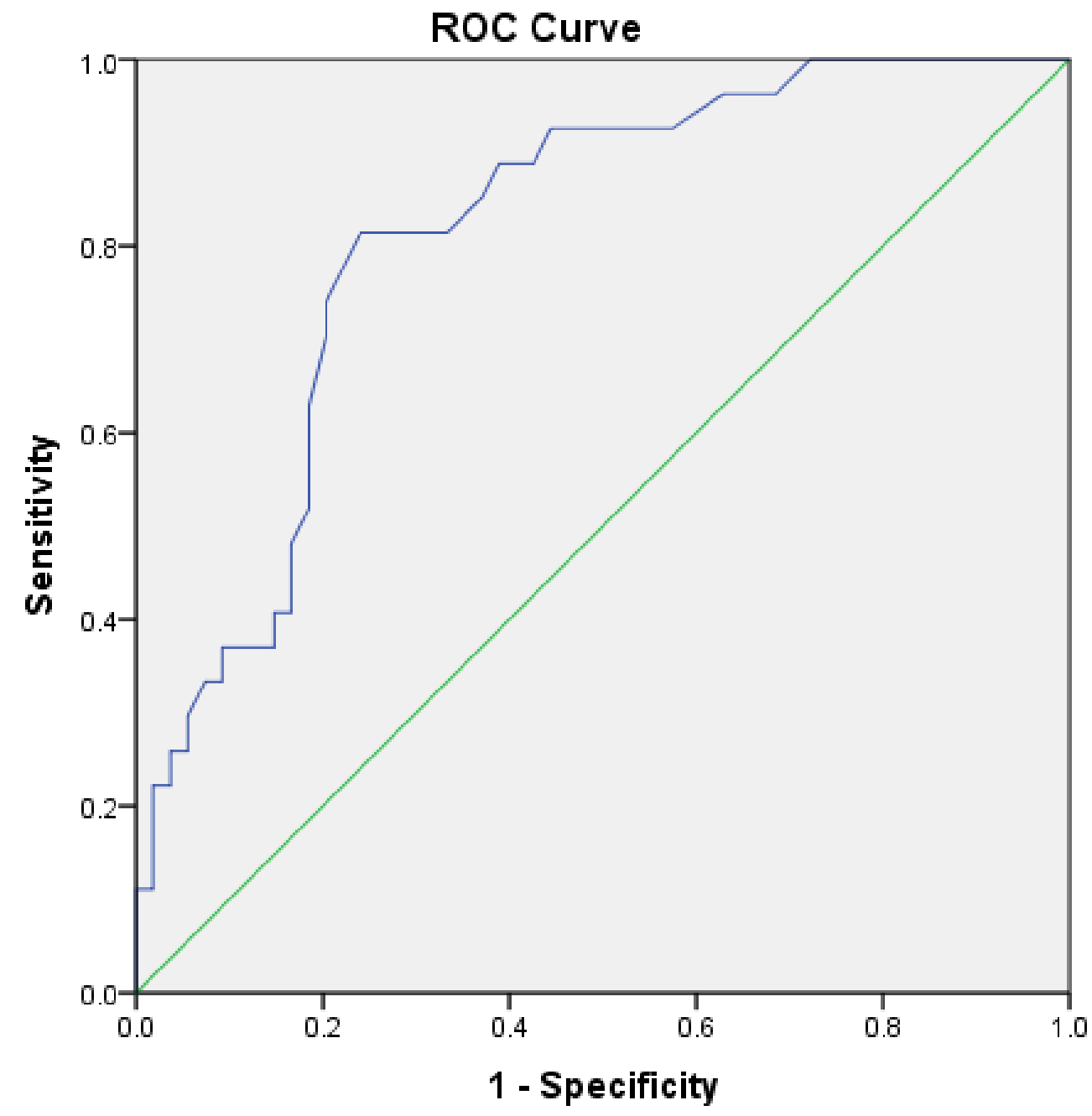

